\title{
Elective, Non-urgent Procedures and Aesthetic Surgery in the Wake of SARS-COVID-19: Considerations Regarding Safety, Feasibility and Impact on Clinical Management
}

\author{
K. Kaye $^{1}$ D F. Paprottka ${ }^{1}$ - R. Escudero' ${ }^{1}$ G. Casabona ${ }^{1} \cdot$ J. Montes $^{2}$ •

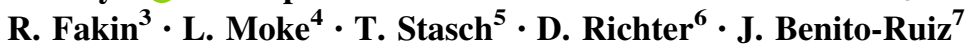

Received: 24 April 2020/Accepted: 4 May 2020/Published online: 14 May 2020

(C) Springer Science+Business Media, LLC, part of Springer Nature and International Society of Aesthetic Plastic Surgery 2020

\begin{abstract}
Background The worldwide spread of a novel coronavirus disease (COVID-19) has led to a near total stop of nonurgent, elective surgeries across all specialties in most affected countries. In the field of aesthetic surgery, the selfimposed moratorium for all aesthetic surgery procedures recommended by most international scientific societies has been adopted by many surgeons worldwide and resulted in a huge socioeconomic impact for most private practices and clinics. An important question still unanswered in most countries is when and how should elective/aesthetic procedures be scheduled again and what kind of organizational changes are necessary to protect patients and healthcare workers when clinics and practices reopen. Defining manageable, evidence-based protocols for testing, surgical/ procedural risk mitigation and clinical flow management/contamination management will be paramount for the safety of non-urgent surgical procedures.

Methods We conducted a MEDLINE/PubMed research for all available publications on COVID-19 and surgery and
\end{abstract}

K. Kaye

Dr.kaye@oceanclinic.net

Ocean Clinic Marbella, Marbella, Spain

2 Torre Medica Auxilio Mutuo, San Juan, PR, USA

3 Ocean Clinic Zurich, Zurich, Switzerland

4 Department of Orthopedic Surgery, University Hospital Leuven, Louvain, Belgium

5 Vitality Fountain Clinic Plastic and Aesthetic Surgery Centre, Nairobi, Kenya

6 Department for Plastic Surgery, Dreifaltigkeitskrankenhaus Wesseling, Wesseling, Germany

7 Antiaging Group Barcelona, Barcelona, Spain
COVID-19 and anesthesia. Articles and referenced literature describing possible procedural impact factors leading to exacerbation of the clinical evolution of COVID-19positive patients were identified to perform risk stratification for elective surgery. Based on these impact factors, considerations for patient selection, choice of procedural complexity, duration of procedure, type of anesthesia, etc., are discussed in this article and translated into algorithms for surgical/anesthesia risk management and clinical management. Current recommendations and published protocols on contamination control, avoidance of crosscontamination and procedural patient flow are reviewed. A COVID-19 testing guideline protocol for patients planning to undergo elective aesthetic surgery is presented and recommendations are made regarding adaptation of current patient information/informed consent forms and patient health questionnaires.

Conclusion The COVID-19 crisis has led to unprecedented challenges in the acute management of the crisis, and the wave only recently seems to flatten out in some countries. The adaptation of surgical and procedural steps for a riskminimizing management of potential COVID-19-positive patients seeking to undergo elective aesthetic procedures in the wake of that wave will present the next big challenge for the aesthetic surgery community. We propose a clinical algorithm to enhance patient safety in elective surgery in the context of COVID-19 and to minimize cross-contamination between healthcare workers and patients. New evidence-based guidelines regarding surgical risk stratification, testing, and clinical flow management/contamination management are proposed. We believe that only the continuous development and broad implementation of guidelines like the ones proposed in this paper will allow an early reintegration of all aesthetic procedures into the scope of surgical care currently performed and to prepare 
the elective surgical specialties better for a possible second wave of the pandemic.

Level of Evidence $V$ This journal requires that authors assign a level of evidence to each article. For a full description of these Evidence-Based Medicine ratings, please refer to the Table of Contents or the online Instructions to Authors www.springer.com/00266.

Keywords Elective surgery - COVID-19 - Patient safety · Aesthetic surgery - Contamination management .

Procedure flow - COVID-19 PCR test - Clinical care protocol $\cdot$ Patient selection · COVID-19 prophylaxis · IGM/ IGG antibody rapid testing $\cdot$ SARS-Cov-2

\section{Introduction and Background}

The outbreak of a novel coronavirus disease in Wuhan, China, in December marked the beginning of unprecedented global spread of the disease, leading to a near collapse of the healthcare systems in most affected countries [1].

In January 2020, the disease was declared a public health concern of international scale by the World Health Organization (WHO) and has been named COVID-19 in February 2020, with SARS-Cov-2 being the name of the causing virus. As the disease is highly contagious and asymptomatic carriers make containment a difficult challenge, it has spread since around the globe with more than 1.5 million confirmed cases worldwide and nearly 100,000 confirmed deaths as of April 10, 2020 [2, 3].

Main transmission vectors were originally thought to be respiratory droplets and direct contact; however, recent publications suggest the possibility of aerosol propagation as well [4-6].

Symptoms may appear 2-14 days after exposure and period incubation ranges from 4 to 7 days, during which any infected patient may be asymptomatic and contagious [8].

The most common symptoms are fever (98\%), anosmia (80\%), cough (76\%), myalgia or fatigue (44\%). About half of the patients present dyspnea. (The median time from onset to dyspnea was 8 days.) All have bilateral, interstitial pneumonia identifiable by their characteristic distribution patterns in chest computer tomography (CT) scans: ground glass opacification (GGO) $(88.0 \%)$, bilateral involvement $(87.5 \%)$, peripheral distribution $(76.0 \%)$ and multilobar (more than one lobe) involvement $(78.8 \%)$. In the majority of documented COVID-19 cases, the initial chest CT is abnormal, even in some patients without any evident symptoms. Follow-up CT in the intermediate stage of disease shows an increase in the number and size of GGOs and progressive transformation of GGO into multifocal consolidative opacities, septal thickening, and development of a crazy paving pattern, with the greatest severity of CT findings visible around day 10 after the symptom onset. Cardiac involvement and arrhythmic complications in COVID-19-positive patients have been described [8-10].

In a cohort of 201 patients with COVID-19 pneumonia in Wuhan, 84 (41.8\%) patients developed ARDS, 53 patients (26.4\%) were admitted to an intensive care unit, 67 patients $(33.3 \%)$ received mechanical ventilation, and 44 patients $(21.9 \%)$ died. Forty-four $(65.7 \%)$ patients who received mechanical ventilation died. Patients developing ARDS were older (difference, 12.0 years; 95\% CI 8.0-16.0 years; $P<0.001)$ and had comorbidities, including hypertension (difference, $13.7 \%$; 95\% CI 1.3-26.1\%; $P=0.02$ ) and diabetes (difference, $13.9 \%$; 95\% CI 3.6-24.2\%; $P=0.002$ ) [11].

In a study comparing European and US data on COVID19, individuals under 65 years old had 34-73-fold lower mortality risk than individuals over 65 years old and accounted for only 5-9\% of all European COVID-19 deaths, with almost all deaths occurring in the range of 40-65 years. Data from three US locations suggest a threefold higher death rate for the same group under 65 years old $(30 \%)$.

In spite of representing 52-64\% of the total age group under 65 years, the subgroup under 40 years of age only accounted for less than $1 \%$ of all European COVID-19 deaths.

The large majority of the COVID-19-related deaths in non-elderly individuals occurred in patients who suffered from underlying diseases: cardiovascular disease, hypertension, chronic obstructive pulmonary disease, severe asthma, diabetes, kidney failure, severe liver disease, immunodeficiency and malignancy [12].

Declared a global pandemic by the WHO on March 11, the sudden surge of COVID-19 brought many affected countries to the limit of their healthcare capacity. Healthcare workers, essential system resources and hospital care space had to be reorganized and reserved for the highacuity care of COVID-19 patients, leading to a near full stop of non-urgent, elective procedures in many countries during the peak of the pandemic [13, 14].

Even without the existence of a legal ban or a declared state of emergency in most affected countries, the scarceness of resources like PPE during the peak of the pandemic, the obvious necessity of liberating available care space in hospitals and the risk of potential complications that could occupy urgently needed ICU beds made it an ethically necessary decision for most national and international aesthetic surgery societies to recommend the temporary stop of all aesthetic, non-urgent surgery [15-17]. 
A growing number of articles are published at this moment covering all aspects of contamination prevention, elevated surgical risk and clinical management of COVID19-positive patients. The question remains if elective surgery is still advisable on infected patients at all or should be generally postponed [18, 19].

There seems to be a general consensus in the current published literature on postponing elective, non-urgent surgery on COVID-19-positive patients. But to our best knowledge, so far no recommendations have been published on when and how to start again carrying out elective, non-urgent surgery on COVID-19-negative patients after the epidemic peak has been reached in a given country or region and the pressure on healthcare facilities, healthcare workers and resources has been released by so far that elective surgery procedures can be safely and ethically programmed again.

The authors think that answering those two questions is of great interest not only for the plastic surgery community, but also for other surgical specialties performing highly elective, non-urgent interventions on a daily basis, which is why specialists from other elective surgery fields were asked to co-author and share their perspective.

"Nothing will be like before after this pandemic," this often-heard statement will be especially true for healthcare providers and surgeons, as the virus will not completely disappear from our societies once the first wave of the pandemic is over [20].

The interventions put into place for virus containment, like restriction of movement, measures to enforce physical distancing, cannot be held in place for an unlimited time, as socioeconomic necessities become more pressing and all affected countries will have to work on a staged exit strategy at a given moment. A study focused on the effects of extending or relaxing physical distancing control measures in Wuhan has suggested that if the measures are gradually relaxed in March, a second wave of cases might occur in the northern hemisphere around mid-summer. The same effect is expectable for all other countries at a later date, meaning that the virus will prevail in society until a vaccine becomes available [21-23].

Until then, as surgeons, we will have to learn to live with a new reality, and we may have to adapt our clinical workflow and to reformulate the way we care for patients. This article aims to give some orientation toward this important task and to serve as base for the formulation of specific guidelines from healthcare providers and healthcare administrators.

The article's first goal is to make a recommendation on the time frame for the reintroduction of elective procedures based on current healthcare strain projections, the healthcare resilience model and projections of virulence. The second goal is to provide the scientific base for solid elective surgery protocols which may be implemented in the moment when a country or region meets the criteria to implement elective, non-urgent procedures.

While we think that both questions can be answered analyzing the plethora of peer-reviewed literature available to date, the second one is much more complex. It involves many variables that influence patient safety and healthcare worker protection and additionally implies some general reflections about risk assessment and risk acceptance in a post-pandemic society.

\section{Methods}

We used a MEDLINE/PubMed research for all available publications in English and Spanish up to April 20, 2020, on COVID-19 AND Surgery, COVID-19 AND Anesthesia, COVID-19 AND Screening, COVID-19 AND Medication to identify existing protocols, preliminary reports on outcomes and published recommendations on surgical care in context with COVID-19. Articles and referenced literature describing possible procedural impact factors leading to exacerbation of the clinical evolution of COVID-19-positive patients were identified and classified. Based on the most commonly discussed denominators, we defined six subsets for the creation of guideline proposals for elective surgery:

- Surgical risk management and risk stratifying

- Perioperative and anesthesia management

- Preoperative testing and screening

- Perioperative pharmacologic prophylaxis

- Clinical management and contamination control

- Patient information and patient consent

The proposed implementation of the recommended guidelines for the six clinical subsets is shown in a general clinical pathway protocol (Fig. 1).

\section{Proposed Time Frame for Implementation of Elective, Non-urgent Surgery Procedures}

To give a recommendation on when elective aesthetic procedures might become practically and ethically feasible again after the epidemic peak has been reached in a given country or region, we propose to use an approach based on the evaluation of healthcare system strain in a given country.

In the authors' opinion, when the COVID-19-related system strain on healthcare facilities, healthcare workers and resources has diminished to levels where the available healthcare resources (hospital beds, ICU beds, materials, tests, PPE, etc.) meet the demand again with a stable positive margin, health administrators can start to plan and 
perform elective surgery procedures in hospitals and clinics which have implemented post-COVID-19 protocols like the ones that will be discussed in this article.

As the infection curve is flattening in a very similar matter in Spain, Italy and Germany, with the USA, the UK, France and Canada lagging around 4 weeks behind, it becomes obvious that the actual strain on healthcare system capacity should normalize within 4-10 weeks and the above-mentioned limitations will gradually disappear. Taking projections for Spain as example, around April 18 COVID-19-related demand for healthcare resources will first drop below the availability baseline, resulting in a

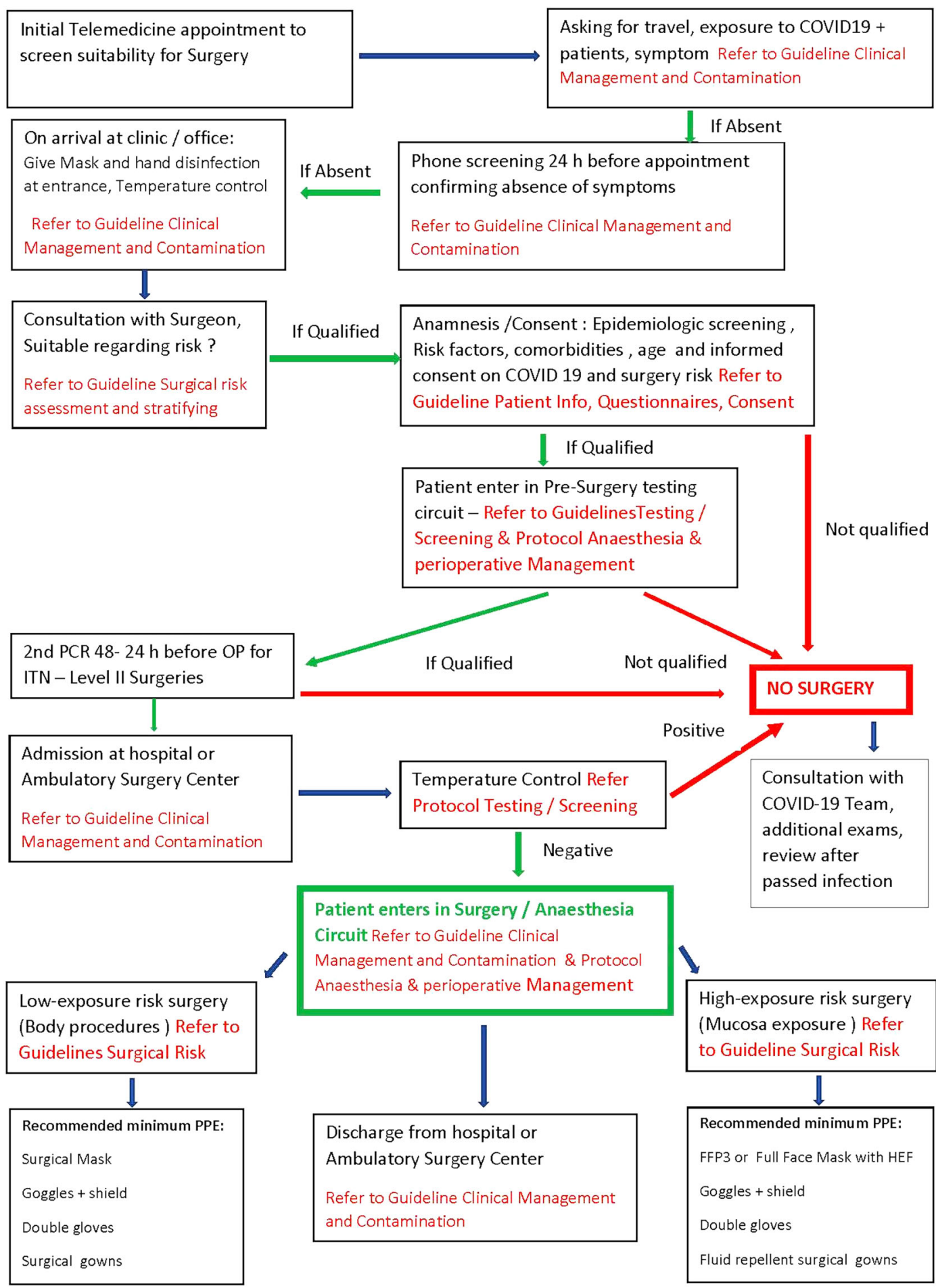

Fig. 1 Flowchart clinical pathway 
positive margin with a stable reserve around April 26, which could be considered by healthcare administrators as possible date for re-implementation of elective procedures. As availability of resources and strain on the healthcare system may vary significantly between regions or even between different healthcare structures locally due to some areas being more affected than, the local conditions prevail and may resume in staged reimplementation of elective surgery throughout one country or nation. The American College of Surgeons recommends using local prevalence and incidence rates and to consider a decrease in measures of COVID-19 incidence for at least 14 days before transitioning to provide surgical services for patients without immediately life- or limb-threatening conditions [24, 25].

Figure 2 shows an example of COVID-19 healthcare strain projections April 24, 2020, for Spain while assuming continued full social distancing. The blue shaded area marks the level of uncertainty of the healthcare strain projection beyond April 24, 2020.

Using such normalization projections on healthcare system strain, including needed/used ratio for ventilators, ICU beds and normal beds may present an adequate approach to decide on the timing when to gradually implement elective surgery procedures into the healthcare panorama.

How far after peak resource use the projected normalization of these ratios occurs will vary largely from country to country or even from one region to another in the same country depending on healthcare system base capacity and system resilience. Healthcare system resilience in the face of a major health crisis is influenced by non-disease immanent factors like governance, financing, service delivery, availability of medicine and equipment, health workers capacity and finally information flow [26].
Differences across countries in the successful control of these factors and long-term underinvestment in health services, as seen in many countries following the 2008 financial crisis, may impair their resilience by depleting their ability to respond to surges and leading to a significantly delayed normalization of healthcare strain.

\section{Clinical Considerations for Reintegration of Elective, Non-urgent Surgery Procedures}

Once that the restrictions of movement for patients have been loosened or lifted and decision has been made to implement elective, non-urgent procedures, every specialty department should thoroughly analyze their clinical and surgical workflow and their procedure/specialty-related risk profile and adapt their institutional clinical guidance protocols for patient evaluation and procedure selection to respond to the new post-pandemic challenges.

In the case of non-urgent elective procedures, especially in the case of aesthetic procedures without a curative indication, surgeons have to be aware that even with a solid routine testing protocol in place for all elective patients there is still a window of uncertainty due to test sensitivity and incubations times [27-29].

As even asymptomatic contacts have shown to be possible transmission vectors, it is the authors' group consensus opinion that every patient should be managed as potentially COVID-19 positive and that all clinical pathways regarding choice of treatment/procedure, pre- and perioperative screening, type of anesthesia, medication, contamination protection/decontamination and patient information/informed consent need to be adapted to this potential risk [30-32]. These measures should be kept in place at least temporarily, until either the herd immunity is achieved in large parts of the population, the virulence has

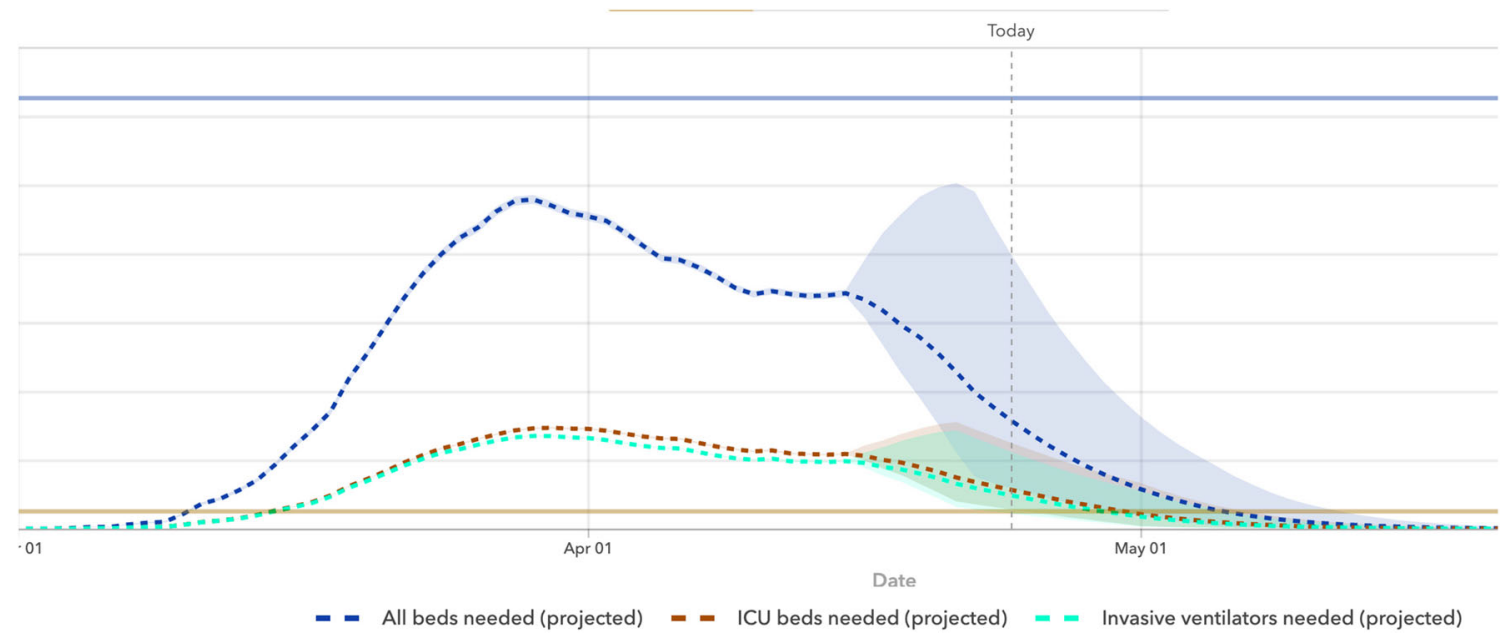

Fig. 2 Healthcare strain projection Spain 
significantly diminished or a vaccine is available. The recommendations on the subset guidelines presented in this article should not be seen and used as isolated clinical pathways, but should be understood as closely interwoven and influencing each other in significant key aspects. This is why some aspects maybe discussed redundantly in the different protocol sections, as they influence more than one clinical decision pathway.

Clinical relevance high_evidence level: moderate

\section{Considerations for Surgical Risk Assessment, Risk Stratifying and Procedure Selection}

There is evidence that the mortality of COVID-19-positive patients undergoing surgery may be higher than the general mortality of the disease, but to date only limited data are available [8].

Aminian et al. reported a series of four surgical patients (cholecystectomy, hernia repair, gastric bypass, and hysterectomy) who developed perioperative complications in the first few weeks of COVID-19 outbreak in Tehran. Three patients developed postoperative fever and pulmonary complications after uneventful elective operations and two patients died [33].

Lei et al. reported a series of 34 patients operated electively during the outbreak. Their conclusion was that surgery may accelerate and exacerbate disease progression of COVID-19. Seven patients (20.6\%) died of COVID-19associated complications (six-sevenfold higher overall case-fatality rate than 2-3\% in COVID-19 patients without surgery. Fifteen patients (44\%) were admitted to ICU, 13 of those $(86.6 \%)$ had Level III surgeries, while the majority of non-ICU patients were Level II surgeries.

Patients admitted to ICU had longer surgical time (median time $200 \mathrm{~min}, P=0.04$ ), were significantly older (median age, 55 years vs. 47 years, $P=0.03$ ) and were more likely to have underlying comorbidities such as hypertension, diabetes and cardiovascular disease. All patients that died had Surgery Level III, longer surgical time and one or more comorbidities. No patient was tested for COVID-19 preoperatively [34].

The proportion of patients receiving ICU care was higher in this cohort (44\%) than the reported $26 \%$ in hospitalized COVID-19 patients without surgery [8].

Another patient series published by Li et al. from thoracic surgery department also suggests the association of higher age and chronic obstructive pulmonary disease (COPD) with disease severity $(P=0.041$ and $P=0.040$, respectively) and death $(P=0.015$ and $P=0.038$, respectively) for COVID-19 patients. In this study, five deaths $(20 \%)$ among hospitalized postoperative patients were reported, leading to the conclusion that patients infected with COVID-19 in the perioperative period have a higher risk of death [7].

Clinical relevance high-evidence level: high

\section{Surgical Risk Stratification}

Based on the limited data evidence available at time of writing of this article, age and presence of comorbidities are primary factors in the prognosis of the disease. In operated COVID-19-positive patients, higher surgical severity Level, general anesthesia and longer duration of surgery seem to correlate with an aggravation of clinical outcome [33, 34].

That is why it must be ensured as much as possible that a patient undergoing an elective operation is COVID-19 negative.

Elective aesthetic plastic surgery could be considered as safe in most cases, due to an overall low morbimortality of the patients, short duration of surgery and Level I-II surgical complexity in most cases. Only a few procedures have been linked to more severe problems (deep venous thrombosis, pulmonary embolism, bleeding) such as large volume liposuction, post-bariatric surgery and recently fat grafting to buttocks, which was linked to a $7 \%$ rate of fat embolism and $3 \%$ rate of mortality [35].

It is controversial if combining procedures are less safe than isolated. Khavanin et al. reported the complication rates among combined procedures $(9.40 \%)$ were greater than those of aesthetic breast surgery $(2.66 \% ; P<0.001)$ but did not significantly differ from abdominal procedures (9.75\%; $P=0.530)$, while Kaoutzanis et al. reported a major complication rate of $0.7 \%$ with hematoma $(0.15 \%)$, pulmonary complications $(0.1 \%)$, infection $(0.1 \%)$ and confirmed venous thromboembolism (VTE) (0.06\%) with liposuction. Combined procedures had a higher risk of confirmed VTE (RR 5.65), pulmonary complications (RR 2.72) and infection (RR 2.41) [36, 37].

Simon et al. found no significant increase in morbidity between the control group and those patients who underwent combined surgical procedures. Abdominoplasty combined with other surgical procedures did not appear to produce significant additional morbidity [38].

Surgical time could be an issue in terms of morbimortality. Analyzing 1800 complex procedures, Krista et al. concluded that surgeries resulting in complications had longer operative times than those that did not $(6.0 \mathrm{vs} .4 .1 \mathrm{~h}$, $P<0.0001)$. Postoperative complications were also associated with obesity $(P<0.001)$, male sex $(P=0.048)$, diabetes $(P=0.0061)$, hypertension $(P=0.0078)$ and renal comorbidities $(P=0.0096)$. Morbidity significantly increased only after $3.13 \mathrm{~h}$, with progressively greater odds increases of 3.05 times after $4.52 \mathrm{~h}$ and 4.71 times after 
$6.77 \mathrm{~h}$. However, facelifts had long procedures times but showed a low complication rate. Therefore, the surgical complexity level has to be considered as important as surgical time [39].

The surgical complexity level may be of importance as well in the context of possible COVID-19+ patients, as the limited data published to date suggesting a higher postoperative morbimortality is based mainly on patients that underwent Level III surgeries [34].

The complexity and surgical time most aesthetic plastic surgery procedures could be considered as Level II. Only combinations of various procedures and post-bariatric surgeries would be considered Level III (Table 1).

Taking into account the evidence discussed above, all these factors should be reflected in the clinical decisionmaking algorithm for any patient planning to undergo elective, no urgent surgery while we are still on the curve of the epidemic. Little is known at time of writing this manuscript if patients could have any long-term sequels after a COVID-19 infection, especially for cases that needed mechanic ventilation during ICU admission. We do not know yet if acquired immunity after infection is protective and lasting, and asymptomatic carriers may be a major problem for the time until a vaccine is available. Until then, our objectives should be:

- To screen all patients to determine who could be operated safely

- To protect negative COVID patients who undergoing an elective operation

- To protect health personnel

Clinical relevance high_evidence level: high

\section{Considerations for Perioperative and Anesthesia Management}

The criteria for patient selection, individual risk stratification and testing during the preoperative consultations with surgeon and anesthetist have been laid out in above (Fig. 3).

Goal of this selection and testing protocol is to minimize the risk to operate on a COVID-19-positive patient and to exclude patients with comorbidities that are associated with possible negative postoperative and post-anesthetic outcome in case of getting infected in the perioperative period [40-43].

The most common factors predicting a risk of a negative post-anesthetic outcome in case of a perioperative COVID19 infection are [40-43]:

1. Age over 65 years

2. ASA 3 or higher

3. NYHA III-IV
4. Emergency surgeries

5. Arterial hypertension.

6. Cerebral vascular disease

7. Ischemic and valvular heart disease.

8. Cardiac arrhythmia

9. Diabetes mellitus

10. Final-stage kidney disease

11. COPD/asthma

12. Obesity.

1. Pre-anesthetic process

Pre-anesthetic consultation The main goal is to identify and exclude symptomatic infected patients, asymptomatic patients within the incubation period/asymptomatic carriers and patients with the above-mentioned comorbidities. The pre-anesthetic clinical record should identify the American Society of Anesthesiologist (ASA) level, the comorbidities, the functional classification and the use of medication [44-46].

Only ASA1 and ASA2 patients with a normal functional classification should be selected for elective, non-urgent procedures [42, 43, 45].

The health questionnaire has to cover signs of acute infection such as fever, dry cough, fatigue, sore throat, anosmia, skin rash or other gastrointestinal symptoms such as diarrhea, anorexia, vomiting, nausea, abdominal pain and/or gastrointestinal bleeding [40, 42, 45, 48-53].

It is important to ask for use of any current or past prophylactic/therapeutic treatment against COVID-19, such as chloroquine and azithromycin, as they are related to an increase in QT-time, which may consequently lead to severe arrhythmia [54-56].

Blood pressure measurement should be included in the standard preoperative workup protocol to exclude arterial hypertension.

The standard preoperative laboratory workup should include a full blood count to identify COVID-19-related alterations such as leukocytopenia and lymphopenia as well as coagulation tests, kidney-liver function and CRP levels, as well as blood sugar levels to exclude diabetes [40, 42, 47, 49, 50, 52, 57, 58].

The preoperative determination of D-dimers levels and ferritin levels, which have been proven to be an indicator for clinical outcome in COVID-19-positive patients, is controversial in the case of negative-tested patients who are planning to undergo elective surgery as published evidence is still weak [47, 59].

Standard chest X-ray has a proven predictive strength and may be included for all patients undergoing intubation anesthesia [46, 47]

Low-dose chest CT scan has an even higher predictive value for an active COVID-19 infection and may be 
Table 1 Levels of surgical complexity

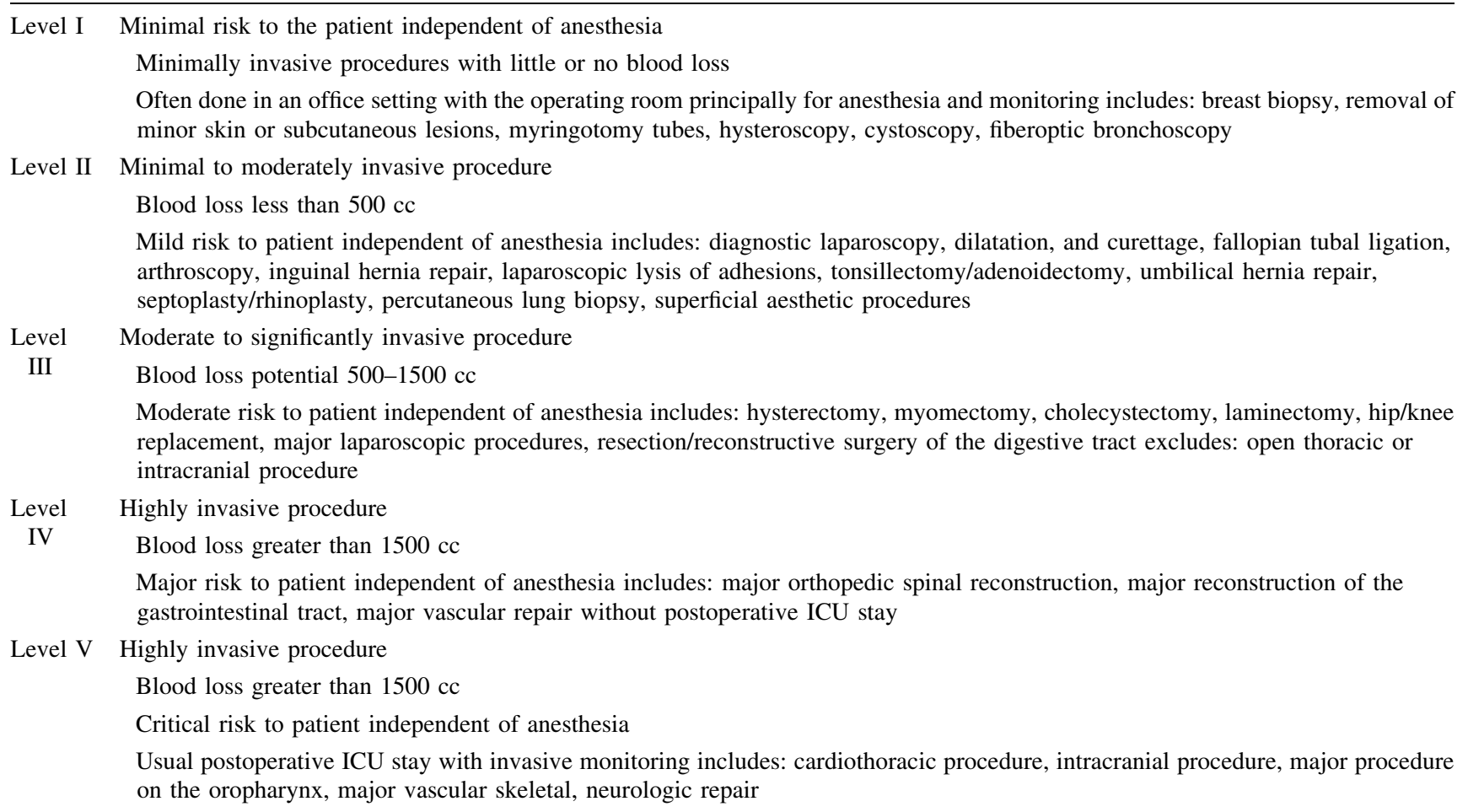

Ambulatory Anesthesiology—a problem-oriented approach. Ed. By Kathryn McGoldrick. Williams and Wilkins 1995. ISBN-13: 978-0683058758

performed in cases where other methods of COVID-19 testing are not available or inconclusive [47, 49, 50]. Clinical imaging should be analyzed for COVID-19-associated peripheral, uni-/bilateral pulmonary infiltration patterns that manifest consistently during the initial phases of the disease [9, 10, 46, 47, 49]. The authors suggest that these recommendations on diagnostic imaging are frequently reviewed by the facility's anesthesiology provider and adaptations are made as soon as the other tests achieve higher accuracy, better predictive power and wider availability.

The limitations of sensitivity and specificity of the currently available tests and the influence of the incubation period on the predictive power of preoperative testing will be discussed in the section on testing of this article. It is the opinion of the authors' group that all cases planned for elective surgery during the descending curve of the disease should be considered as potentially infectious, and therefore hospitals and other medical establishments should take the appropriate precautions regarding the prevention of the propagation of the disease, especially with regard to patients residing in high-risk areas [45, 60].

Clinical relevance high-evidence level: high

\section{Anesthetic process}

Upon arrival to the hospital or the ambulatory surgery center, it is essential to rule out again any signs suggestive for COVID-19 infection. Patients must have their temperature taken, use facial masks and undergo hand disinfection before being admitted to the ward. In hospitals, separated patient circulation pathways must be established for negative tested patient coming for elective surgery and non-tested/COVID-19-positive (confirmed or suspected) cases.

\section{Induction/Premedication}

The rest of the preoperative medication, especially when using either ondansetron or droperidol, must be used with special precaution as there is a possible risk in the QT-time as described above.

In the premedication, it is recommended to use prophylactic antibiotics and antiemetic drugs [45]. In the latter, the use of ondansetron and droperidol is recommended instead of the use of dexamethasone as it can increase the risk of viral spread in COVID-19-positive patients, as well as delay the elimination of the virus [45, 49, 53, 61-64]. 


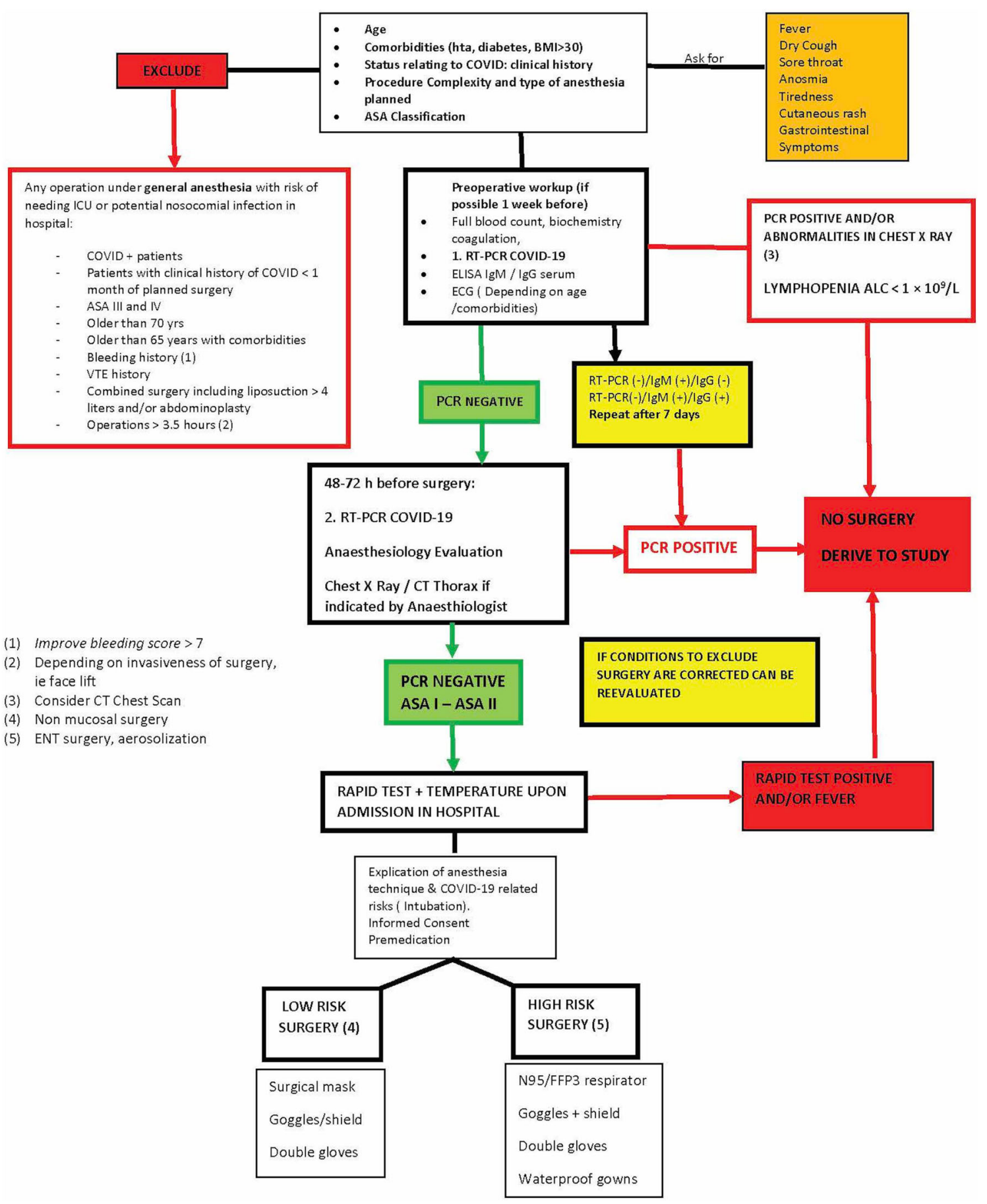

Fig. 3 Algorithm for risk stratification

After completion of the anesthesia checklist upon arrival of the patient in the induction area or operating room, monitoring and IV lines will be placed, and induction is performed following the institutional protocols for the chosen anesthesia technique [45, 62].

\section{Regional/Tumescent Anesthesia with or Without Sedation}

Regional/tumescent with or without conscious sedation should be regarded as the first and most important option for elective surgery during the post-COVID-19 curve as it avoids invasion of the tracheal-bronchial tract. 
This anesthesia modality should be performed whenever complexity of surgery and anatomic location allow, and may include the following categories: neuraxial anesthesia, ultrasound-guided peripheral nerve block and tumescent anesthesia. The equipment used for visualization, such as ultrasound probes, must be efficiently protected/isolated and disinfected after use following the COVID-19 decontamination guidelines discussed in this article [41, 50, 65-67].

The anesthetist should use PPE including gown, gloves, FFP2 facial masks and surgical cap. In cases that the sedation has to be converted into general anesthesia, double gloves, facial shield and/or goggles should be added [41, 46, 51, 53, 66, 69].

If intravenous sedation is used in combination with regional anesthesia for hemodynamic stability and/or patient comfort, only conscious sedation must be attempted in order to avoid respiratory depression and cough [67].

If oxygen is needed, it should be applied in low flow to guarantee optimal hemoglobin oxygen saturation.

During this process, the patient must keep his surgical mask on and gloves on in order to reduce the risk of contamination, the oxygen should be applied over nasal cannula under the surgical mask [45].

Sedation as an anesthetic technique has a higher risk of major respiratory complications as well as a major risk of contamination through aerosolized particles; therefore, the technique should be avoided when treating COVID-19infected patients and used with precaution only on healthy patients in elective cases. In cases in which the regional anesthetic technique with sedation is not sufficient, the procedure has to be converted to general anesthesia following the guidelines described in the following $[41,45,66]$.

If local anesthetic systemic toxicity (LAST) occurs, treatment must occur in accordance with the guidelines of the American Society of Regional Anesthesia and Pain Medicine [65, 68].

\section{General Anesthesia}

In case of general anesthesia, the patient should be preoxygenated with $100 \%$ oxygen over 5 min using a completely sealed facial mask. Manual bag ventilation should be avoided in these cases [45, 66, 69-71].

Rapid sequence intubation (RSI) is recommended using atropine/glycopyrrolate to reduce secretion, lidocaine, propofol, rocuronium, as well as dexmedetomidine. Ideally trans-oral endotracheal intubation (EI) with video laryngoscope should be used. Once the correct positioning of the tracheal tube is established, it must be sealed immediately by cuff inflation [41, 43, 45, 51, 53, 54, 66, 69, 70, 72-77].
The anesthetist should use PPE including long sleeved gown, double gloves and FFP2 facial masks, goggles, facial screen and surgical caps [41, 46, 51, 53, 66, 69]. To avoid dispersion of particles, a drape forming a pocket can be placed over the patients head during intubation.

In case of COVID-19-positive patients, the use of laryngeal masks or supraglottic devices is controversial as these could cause aerosolization of infectious particles and therefore should be strictly reserved in cases of difficulties in intubation or ventilation $[45,66]$.

In healthy, negative-tested patients undergoing elective surgery, the use of these devices might be advantageous due to lack of invasion of the tracheal-bronchial tract and reduced ventilation pressure.

At time of writing of this article, it is unclear whether intravenous anesthesia should be performed or whether inhaled anesthesia should be favored [45]. The choice of the applicable technique will be dependent on each case and the conditions of the patient. The authors favor the maintenance of the anesthesia with sevorane and dexmedetomidine to limit the use of opiates, as they may induce perioperative nausea and vomiting with a higher risk of contamination through aerosols and coughing and present a higher risk of immunosuppression [78]. The use of low doses of neuromuscular blockers is also advisable [69], thus avoiding the risk of postoperative respiratory depression.

Ventilator setting should use a tidal volume between 4 and $8 \mathrm{ml} / \mathrm{kg}$ (optimal $6 \mathrm{ml} / \mathrm{kg}$ ), with plateau pressure under $30 \mathrm{mmHg}$ and $50 \% \mathrm{FIO}_{2}$ to minimize the risk of atelectasis. The use of positive end-expiratory pressure (PEEP) should be optimized for adequate oxygen saturation level and pulmonary recruitment. The use of extremely reduced or superhigh fresh-gas flow is contraindicated due to the risk of contamination in the anesthesia machine and the operating room. The exhalation gases must be connected to active scavenging elimination system [45, 69, 70, 73, 76, 77].

To avoid spreading of infectious particles though the anesthesia machine, the circuit should be equipped with two HME filters, one of them located close to the patient and the other filter located in the respiratory arm of the machine. These filters and the breathing circuits, as well as other disposables, should be discarded at the end of every anesthetic case [45, 66, 74, 76, 79].

It may not be required to change the $\mathrm{CO}_{2}$ absorbers; however, it is of great importance to change the $\mathrm{CO}_{2}$ sample lines [61, 71, 74, 76, 79].

The combination of regional anesthesia described above with general anesthesia can provide multimodal analgesia effectively reducing the need for NSAIDs and opiates, reserving the latter only for cases of analgesic rescue [45, 63]. Although there is yet not enough evidence published, the use of non-opiate general anesthesia could be 
beneficial for elective, non-urgent procedures in the postpandemic wake of COVID-19.

\section{Extubating and Recovery}

Once the surgical procedure is finished, the awakening of the patient should be done gently using maneuvers which reduce the risk of coughing, respiratory depression, nausea and vomiting. To avoid this, the use of dexmedetomidine and lidocaine is recommended. For extubation after EI, a sterile drape can be placed over the anesthetist and the patient to reduce contamination through aerosolization during extubation; in sedation, the use of surgical masks is essential for avoiding viral dispersion. Furthermore, the reversal of neuromuscular blocks using pharmacological antagonists as sugammadex is recommended. The use of neostigmine must be avoided due to the risk of increasing the secretion [45, 60, 69, 72, 75, 77].

The protection of the healthcare staff should be maintained by the use of double gloves, facial masks, goggles, during extubation, and presence of staff kept to minimum necessary. After the patient has been transferred to the recovery unit and later to the ward, all medical/intubation equipment, anesthesia stations and all surfaces in operating rooms and in recovery rooms have to be decontaminated following the recommendations laid out in the section Contamination Management of this article [40, 46, 47, 61, 79].

In the recovery room, it is essential to deliver the required supportive care while assuring the hemodynamic and respiratory stability and ensuring temperature control [45].

The same regional anesthesia techniques as described above can be used as the first step in the multimodal anesthesia to achieve effective pain control why reducing the need for NSAIDs and opiates. Low-dose flow of oxygen should be used if needed.

Clinical relevance high—evidence level: high

\section{Considerations for Preoperative Testing and Screening}

During the height of the pandemic, the decision to test patients for COVID-19 was based on clinical and epidemiological factors and linked to an assessment of the likelihood of infection [80]. Symptomatic patients or mildly symptomatic patients were tested if they had contact with a COVID-19 case. In the scenario of planning elective surgical procedures in the aftermath of the pandemic, where many patients may still be at risk of infection, may be infected but asymptomatic or are immune to the condition, it is prudent to engage a screening protocol to optimize safety for both patient and health workers. We assume that only patients should be considered for elective procedures that are asymptomatic and have not been exposed to infected individuals in the past 14 days. In order to evaluate their infectious status, preoperative testing for COVID-19 is mandatory.

At the time of writing this paper, many aspects of the virus and COVID-19 disease are not fully understood, and diagnostic tests for the virus are being developed, validated and optimized. In the preoperative planning, surgical patients should undergo a combination of molecular and antibody-based serological tests. The two most commonly used assay groups are being described briefly:

\section{Reverse-Transcriptase Polymerase Chain Reaction (RT- PCR) Tests}

PCR is a very common molecular scientific technique that has been widely used in research and medicine for many years to detect genetic information. RT-PCR is a special version used when RNA is being detected and it is now being used as a test to detect SARS-CoV-2, the virus causing COVID-19. Nucleic acid amplification tests (NAAT) of respiratory secretions using the real-time reverse-transcriptase polymerase chain reaction have been proven to help identifying the virus in the early disease stages by detecting unique sequences of virus RNA [81]. Availability of different assays using the RT-PCR technology has helped in patient detection and efforts to contain the virus, since it detects presence of virus very early in the infection [82].

RT-PCR tests are quick, sensitive and reliable, capable of producing results in a few hours in a local laboratory, although this may take longer if samples must first be sent to specialized external laboratories. Many diagnostic and research companies produce RT-PCR products, tests and machines, so the technology is widely available and is becoming cheaper. Some RT-PCR tests are developed as an "all-in-one" kit, reducing laboratory handling and potential for contamination [83].

The first step in any diagnostic coronavirus test is to get a good-quality sample. A sterile swab/brush is passed through the nose into the nasopharynx or through the oral cavity to the oropharynx and left for several seconds to absorb secretions [84]. The test may be uncomfortable for the patient as it may irritate the nasal passage or the uvula.

Although a simple throat swab will provide sufficient sensitivity to detect an early stage of infection [85], a total of two swabs of the upper respiratory secretions (nasopharyngeal or oropharyngeal swab) or lower respiratory specimen (sputum) are recommended to improve the specificity of the test [86]. A common criterion for discontinuation of transmission-based precautions is a 
negative RT-PCR result from two sets of nasopharyngeal and throat swab specimens on two consecutive days [87].

Other means of collecting samples are from saliva, bronchial lavage, or stool.

Because a lot of recent research and development has gone into RT-PCR assays used for COVID-19, results that took days or a few hours to process are now available in minutes. Most molecular tests have been approved by the United States Food and Drug Administration (FDA) under emergency use authorization and are Conformité Européenne (CE) marked [88]. These molecular RT-PCR assays are fairly reliable if performed on a sample taken from an infected part of the body during active infection, with a very high sensitivity and specificity [89]. A positive test result means that patient tested as a current, active infection.

A negative PCR result can mean that the person is truly not currently infected by this virus, or presents a falsenegative result because the virus is not present at the sites where the sample was taken from, or the sample taken was of poor quality or too small, or that it is too early/too late in the infection to detect virus RNA. Other reasons for falsenegative results could be laboratory handling errors or technical reasons $[86,90]$.

During the height of the pandemic, chest computerized tomography (CT) scans acted as a complementary diagnostic tool enabling physicians to effectively detect COVID-19 infection in several RT-PCR false-negative cases [91]. In the elective surgery scenario, negative test results require new patient samples to be taken a week later to further reduce the chance of missing an infected person.

The RT-PCR test cannot detect if a person has had the virus and then cleared it after the end of the COVID-19 disease, i.e., whether a person had the disease, as it only detects when active virus is present. The authors group therefore recommends adding an antibody test to the preoperative workup.

\section{Clinical Relevance of RT-PCR Tests}

Patients with COVID-19 have demonstrated high viral loads in the upper respiratory tract soon after their infection, with the highest load assumed to be the day before symptoms appear. Therefore, the asymptomatic patient carrier contributes to the rapid and wide spreading of the virus.

Considering a mean incubation period of about 5 days, infectiveness of a patient will start 2-3 days before symptom onset, with the peak 1 day before symptom onset [92]. Studies show that viral shedding is highest when the viral load is at its peak, and gradually decreases within 7 days as patients' progress through the course of their disease, slowly reaching their detection limit about 3 weeks later [93].

Figure 4 shows a schematic representation of the evolution of SARS-COV-2 virus and antigen; however, recent evidence points to a possible shift of the peak of the curve toward the left, which would indicate an earlier peak than represented in the diagram. Further evidence and more studies are needed to confirm these findings.

RT-PCR tests have proven to be valuable in establishing a diagnosis of COVID-19 with high sensitivity and specificity. In addition to these diagnostic tests that are used to confirm the presence or even viral load, antibody tests can help to determine whether or not someone was previously infected even if that person was asymptomatic [94].

Clinical relevance high-evidence level: high

\section{Antibody or Antigen Tests (Lateral Flow Tests and ELISA)}

Several different serology immunoassays based on antibody or antigen detection are currently available and are used to complement the molecular assays of RT-PCR for the diagnosis of COVID-19. The most prominent immunoassays are rapid lateral flow immunoassays (generally called rapid diagnostic tests (RDTs) and manual enzyme-linked immunoassay (ELISA). They are crucial to identify viral reservoir hosts and patients who have become immune to the disease [88]. Serological tests are cheaper to perform than RT-PCR, with falling prices to be expected as more companies get official approval for their products.

\section{Lateral Flow/Rapid Diagnostic Test (RDT)}

Rapid point-of-care immunoassays have been developed using lateral flow technology to detect antigens of the SARS-CoV-2 virus and detecting antibodies (IgM and IgG) produced by COVID-19-infected patients. This qualitative assay is small and portable, often resembling a pregnancy test, showing the user colored lines to indicate positive or negative results. These tests may use blood samples from a finger prick, saliva samples or nasal swab fluids. RDTs do not measure the quantity of antibodies in the patient serum, or if these antibodies are able to protect against future infection [95], but they have the ability to detect a passed infection and can identify people who were asymptomatic and people who cleared the virus and are no longer at high of risk being infected or of spreading the virus.

The accuracy of results obtained by some rapid tests correlates well with that achieved by RT-PCR. However, since lateral flow antibody tests can be produced quickly and cheaply, many such tests have come onto the market recently. Many tests available to date lack analytical 
Fig. 4 Antigen/antibody curve

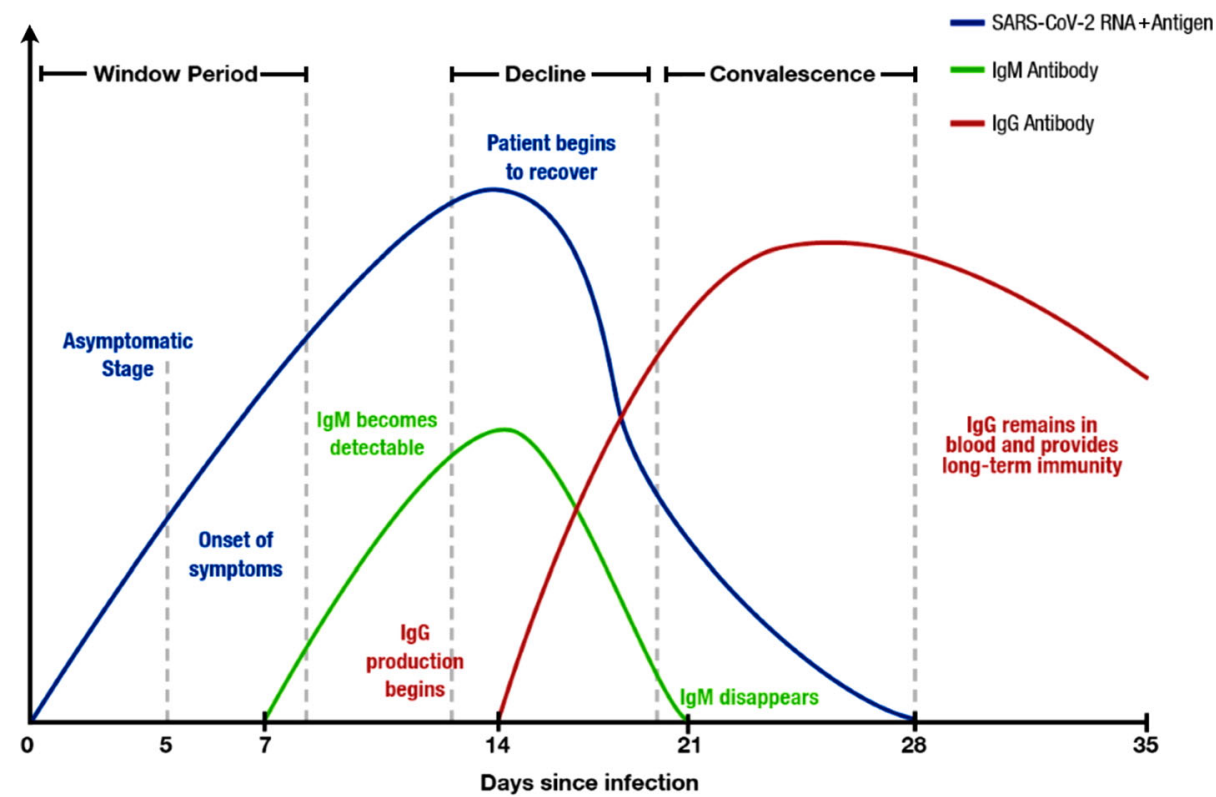

performance regarding sensitivity/specificity and need to be tested and validated before getting approval.

Antigen lateral flow immunoassays present a newer technology with additional scientific and technical challenges, which mean they are not likely to be fully developed during the pandemic period. These antigen assays detect the virus directly without the amplification steps needed for RT-PCR, and like those they are only able to detect current active viral infection [83]. Another testing concern is the variability of viral loads in COVID-19 patients, leading to false-negative antigen detection due to low viral load or sampling variability [96]. Lateral flow tests are more expensive and time-consuming for large batch testing than laboratory-based antibody tests such as ELISA.

\section{Enzyme-Linked Immunosorbent Assay (ELISA)}

An ELISA is a common biochemical technique used to detect antigens or antibodies, depending on the type of test used. This test can be qualitative or quantitative and is generally a laboratory-based test often taking several hours for results to be available. These tests usually use whole blood, plasma or serum samples from patients. The test relies on a plate that is coated with a viral protein of interest, such as the spike protein. Patient samples are then incubated with the protein, and if the patient has developed COVID-19-specific antibodies (IgG and IgM), they bind together. The bound antibody-protein complex can then be detected with another wash of antibodies that produce a color or fluorescent-based readout. It is a cheap and timeeffective method for batch testing of large numbers of patient samples at the same time.
A positive ELISA test will indicate that the patient has seroconverted (produced antibodies to the infection) and is either currently infected, or has had an infection in the past. A negative test would mean that the patient has not been infected, or did not develop an immune response yet.

\section{Neutralization Assay}

This test examines the ability of antibodies to prevent viral infection of cells in in vitro setting and is usually used to confirm whether a positive antibody test is specific to the investigated pathogen in question. Neutralization assays are used to prove if a patient has antibodies that are active and effective against a given virus, even if the patient has already passed the infection. These tests require whole blood, serum or plasma samples from the patient. Neutralization assays depend on cell culture, a laboratory-based method of culturing cells that allow SARS-CoV-2 growth. Virus and cells are cultivated with decreasing concentrations of antibodies to quantify how many antibodies in the patient serum are able to block virus replication. This assay is more important for understanding how antibody tests can be qualified and quantified, and only plays a minor role in the pre-op preparation of patients. Validation and improving sensitivity and specificity of antibody assays are important to limit cross-reactivity. Similar protein structures to other coronaviruses are responsible for this and can lead to false-positive results $[90,97]$. These are then further tested and improved with the neutralization tests [98].

A lot of research is currently being conducted to improve serological antibody tests, which will be more accurate to detect COVID-19 infection or immunity. The sensitivities of currently available assays are further 
validated [93], and new tests with higher accuracy may become available soon.

\section{Clinical Relevance Serological Antibody Tests}

It has been shown that patients with COVID-19 infection showed serological responses, including COVID-19 virusspecific IgM and IgG [85]. IgM antibody can be detected as early as day 3 in many infections. Seroconversion (detectable antibodies) in a patient cohort in Germany with mild COVID-19 symptoms occurred in half of all patients by day 7, and in all by day 14 [84]. An Italian paper showed that serological rapid tests are not useful for diagnosing COVID-19 in the acute setting [29], when the RT-PCR is more useful. Other studies showed that $\operatorname{IgM}$ is detectable in samples from 10 to 30 days after SARS-CoV2 infection, while $\mathrm{IgG}$ can be detected from 20 days onward [89]. The IgM response occurs earlier than that of IgG, but then decreases and disappears. While IgG can persist after passed infection for a long time, their protective role in case SARS-CoV-2 is still under investigation [88]. Although it appears that recovered COVID-19 patients have antibodies for at least 2 weeks, long-term data are still missing, and it is suggested that antibodies might be present in the blood sample for many months to years. Figure 4 shows this response schematically. More results from current and future studies need to be evaluated in order to improve the accuracy of the diagram shown in relation to COVID-19.

IgM responses are notoriously non-specific, and given the time required to develop specific IgG responses, serology detection is not likely to play a major role in active case management except diagnose/confirm late COVID-19 cases, to determine the immunity of healthcare workers, or used as a risk stratification to identify patients for elective surgery [96].

Clinical relevance high_-evidence level: high

\section{Recommendations on Testing for Elective Surgery Patients}

During initial consultation, patients will be stratified according to their risk profile, and the level of operation planned is identified. They will be informed that preoperative testing for COVID-19 will be necessary in order to proceed with surgical planning.

All elective patients should be tested prior to scheduling surgery in order to make sure that only patients without COVID-19 infection will undergo a procedure. Since all patients can be potential carriers of the virus, we propose the following protocol, designed to protect both patients and medical staff. The basis of the guideline is to identify and rule out patients who might be in the asymptomatic window period but are already infected with the virus. For this, we suggest to perform staged testing at two separate time points:

The first-line testing should include a RT-PCR test, as well as a serological RDT for $\operatorname{IgM}$ and $\operatorname{IgG}$ antibodies during routine preoperative workup. Ideally performed 1 week before the planned procedure, adaptation to local conditions and pre-op pathways may be necessary. The second-line testing should include another RT-PCR 48-72 $\mathrm{h}$ before the surgery. An additional serological rapid diagnostic test (RDT) may be optionally performed at time of admission. Before implementation, healthcare administrators may have to adapt the proposed timeline to the clinical workflow of their facility.

Such a testing array will identify all patients already infected before the pre-op workup day, but presented a false-negative RT-PCR and still negative antibody tests at the time of pre-op. These patients should test positive for RT-PCR and/or for antibodies a week later, since most studies support a median incubation time of 5-6 days. This protocol will also identify patients who are infected but completely asymptomatic.

Patients who pass both RT-PCR tests should be requested to self-isolate in their homes during the following $24-48 \mathrm{~h}$ prior to the surgery with special precautions to prevent potential infection by family or friends. Wearing a facemask when coming to the hospital/clinic and enforcing social distancing at all times is strongly recommended.

\section{RT-PCR Results}

Patients testing positive for the RT-PCR tests at any stage should be isolated and referred to the COVID-19 response team, as this will indicate an active infection.

If the RT-PCR tests are negative on both occasions, the patient can be operated following the second test, while adhering to standard operating health and safety protocols in theater. Any further investigations will depend on the patient's medical history, surgeon's preference and planned procedure.

\section{Serological Antibody Results (RDT)}

Positive antibody tests have to be qualified if they are positive for IgM or IgG, or both.

If both initial $\operatorname{IgM}$ and $\operatorname{IgG}$ tests are negative, the patient will be prepared for surgery and tested again $24-48 \mathrm{~h}$ prior to the surgery at least 1 week later using the RT-PCR test and RDT. If the PCR is negative and $\operatorname{IgM}$ test is positive, the patient may still undergo the surgical workup. The retest after 1 week will determine whether the surgery may take place or not. If the PCR is negative and IgG test is 
positive, the patient may undergo the surgical workup since it indicates passed infection. All further scenarios of possible result combinations of RT-PCR and RDTs are summarized in Table 2.

Clinical relevance high—evidence level: moderate-high

\section{Testing Recommendations for Health Workers Involved in Elective Operations}

In the literature, there are various recommendations on how medical staff who were involved in surgical procedures with COVID-19 patients should be tested. Some were required to have a SARS-CoV-2 virus detection test (RTPCR of nasopharyngeal swabs) and CT scans once every 2 weeks [99], while others tested front-line workers with RT-PCR tests only when they were symptomatic [100]. We recommend regular testing of all staff involved in patient care in the post-COVID-19 context using RT-PCR tests whenever HCW shows COVID-19-associated symptoms, and monthly RDTs for possible antibody responses. Depending on local protocols and national reporting requirements, both positive and negative results should be reported to the national authorities.

Clinical relevance high—evidence level: moderate

\section{Considerations on Perioperative Pharmacologic Prophylaxis}

Since every major surgical intervention results in stress for the patient's body and immune suppression during the postoperative recovery may occur, a patient undergoing elective surgery should to be as well prepared as possible, especially during the descend of the pandemic curve [101, 102].

In addition to the preoperative standard blood analysis, it could be considered to include vitamin $\mathrm{C}$ and D levels, zinc and blood iron levels and thyroid hormones (T3 and T4) in the preoperative workup. If alterations of any kind are detected, they should be corrected before the patient undergoes elective surgery. In case of major procedures (Level II or $>2 \mathrm{~h}$ ), a probiotic treatment can be initiated 2 weeks before the planned procedure to regulate the balance of intestinal micro biota and reduce the risk of secondary infection due to bacterial translocation in possible COVID-19 patients [103].

Vitamin B12, copper, folate and selenium also play an important role in the immune system response and therefore could also be tested [104, 105].

Vitamin D and curcumin have both shown positive effects on the intestinal microbiome, in particular the lactobacilli, which synergistically support probiotic therapy [106, 107].

Data on efficient preventive medications in the context surgery and COCID-19 are still limited; but we believe an optimal preparation of every patient for planned, non-urgent surgery during the curve and until the availability of a vaccine.

The most relevant supplements and medications are listed below in the order of clinical relevance for a possible preventive treatment approach. The evidence of current publications is still scarce, and larger clinical trials are needed in the authors' opinion before formulating strong clinical guidelines for the perioperative use of those substances.

\section{Vitamin D}

Vitamin D is known to mitigate the scope of acquired immunity and regenerate endothelial lining. This may be beneficial in minimizing the alveolar damage caused in ARDS. One study showed that there is a $12 \%$ overall protective effect of vitamin $\mathrm{D}$ supplementation against bacterial and viral acute respiratory tract infection. These protective effects increased to $19 \%$ in those individuals on the daily or weekly regimen of vitamin D compared to those dosing on a monthly bolus of vitamin D. Furthermore, there is a $70 \%$ protective effect when vitamin $\mathrm{D}$ deficiency is corrected with supplementation. This result is relevant to the majority of individuals residing in lowsunlight countries that experience vitamin $\mathrm{D}$ deficiency due to extended periods of lack of sunlight [108]. Therefor, low vitamin D levels may also be expected during the first phase after confinement ends.

In addition to the general immune system strengthening properties of vitamin $\mathrm{D}$, the expression and functionality of ACE2 are reduced by vitamin D, reducing the virus's ability to dock on the cell. Furthermore, vitamin D alleviates lipopolysaccharide-induced acute lung injury via regulation of the renin-angiotensin system (RAS) [109]. The vitamin D substitution should always go along with the intake of magnesium in order to achieve a higher absorption rate or being better protected against over-dosing [109]. Vitamin D levels should be checked on a regular basis after being supplemented.

Clinical relevance level: high—evidence level high

\section{Curcumin}

Another interesting treatment approach is the perioral substitution of curcumin. Curcumin is a bright yellow chemical produced by Curcuma longa plants. It is the principal curcuminoid of turmeric (Curcuma longa), a 
Table 2 Algorithm for handling of RT-PCR and ELISA Test results combinations

\begin{tabular}{|c|c|c|}
\hline $\begin{array}{l}\text { If PCR }- \text { and } \\
\text { ELISA- } \\
(\operatorname{IgM}-\operatorname{IgG}-)\end{array}$ & No infection or undetectable infection & $\begin{array}{l}\text { Retest after } 1 \text { week with PCR. If retest is also negative, proceed } \\
\text { to pre-op workup. If retest is positive, refer to COVID- } 19 \\
\text { team }\end{array}$ \\
\hline $\begin{array}{l}\text { If PCR+ and } \\
\text { ELISA- } \\
(\operatorname{IgM}-\operatorname{IgG}-)\end{array}$ & No infection or undetectable infection & $\begin{array}{l}\text { Retest after } 1 \text { week with PCR. If retest is also negative, proceed } \\
\text { to pre-op workup. If retest is positive, refer to COVID- } 19 \\
\text { team }\end{array}$ \\
\hline $\begin{array}{l}\text { If PCR+ and } \\
\text { ELISA- } \\
(\operatorname{IgM}-\text { IgG-) }\end{array}$ & Early window period of infection & Refer to COVID-19 team \\
\hline $\begin{array}{l}\text { If PCR+ and } \\
\text { ELISA+ } \\
(\operatorname{IgM}+\text { IgG-) }\end{array}$ & Early phase of infection & Refer to COVID-19 team \\
\hline $\begin{array}{l}\text { If PCR }+ \text { and } \\
\text { ELISA+ } \\
(\operatorname{IgM}+\text { IgG }+)\end{array}$ & Active phase of infection & Refer to COVID-19 team \\
\hline $\begin{array}{l}\text { If PCR }+ \text { and } \\
\text { ELISA+ } \\
(\operatorname{IgM}-\operatorname{IgG}+)\end{array}$ & $\begin{array}{l}\text { Late phase of infection with active virus with } \\
\text { seroconversion or recurrent stage of infection }\end{array}$ & Refer to COVID-19 team \\
\hline $\begin{array}{l}\text { If PCR }- \text { and } \\
\text { ELISA+ } \\
(\operatorname{IgM}+\operatorname{IgG}-)\end{array}$ & $\begin{array}{l}\text { Patient may be in early phase of infection with } \\
\text { seroconversion or false-negative PCR result or false- } \\
\text { positive IgM result }\end{array}$ & $\begin{array}{l}\text { Retest after } 1 \text { week with PCR and RDT and refer to COVID- } \\
19-19 \text { team if positive. If retest is negative, proceed to pre-op } \\
\text { workup }\end{array}$ \\
\hline $\begin{array}{l}\text { If PCR }- \text { and } \\
\text { ELISA+ } \\
(\operatorname{IgM}+\operatorname{IgG}+)\end{array}$ & $\begin{array}{l}\text { Possible recovery-stage COVID-19 patient, or false- } \\
\text { negative PCR result }\end{array}$ & $\begin{array}{l}\text { Retest after } 1 \text { week with PCR and RDT and refer to COVID-19 } \\
\text { team if positive. If retest is negative, proceed to pre-op } \\
\text { workup }\end{array}$ \\
\hline $\begin{array}{l}\text { If PCR }- \text { and } \\
\text { ELISA+ } \\
(\operatorname{IgM}-\operatorname{IgG}+)\end{array}$ & Possible recovered COVID-19 patient, likely immune & Proceed to with pre-op workup \\
\hline
\end{tabular}

member of the ginger family, Zingiberaceae. Chemically, curcumin is a diarylheptanoid, belonging to the group of curcuminoids, which are natural phenols responsible for turmeric's yellow color. It can cause side effects, such as nausea, diarrhea, hives, or dizziness. Interestingly, the expression of TMPRSS2 is inhibited by curcumin. This means that with the intake of curcumin, in addition to its properties that fundamentally support and promote the immune system and its overall anti-inflammatory properties, curcumin may also have a specific anti-COVID-19 property. Further clinical trials are needed to verify this theory $[110,111]$.

Clinical relevance level: moderate/high-evidence level low

\section{Vitamin C}

Regarding prevention with Vitamin C (L-ascorbic acid), there is no evidence so far that taking vitamin $\mathrm{C}$ will help prevent infection with the SARS-CoV-2. Vitamin $\mathrm{C}$ is an important nutrient that keeps your immune system functioning properly. It stimulates neutrophil chemotaxis and contributes to maintaining the redox integrity of cells thereby protecting them against reactive oxygen species. Eating a variety of fruits and vegetables is recommended to cover the daily demand.

Additionally, a recent meta-analysis showed that both oral and IV high-dose vitamin $\mathrm{C}$ treatment may aid people admitted to intensive care units (ICU) for critical illnesses by reducing ICU stay length by $8 \%$ and shortening the duration of mechanical ventilation by $18.2 \%$ [112].

In a scientific study focusing on patients with sepsis and ARDS, a 96-hour infusion of vitamin C compared with placebo could not significantly improve organ dysfunction scores or alter markers of inflammation and vascular injury [113].

Another study came to the conclusion that regular prophylactic intakes of vitamin $\mathrm{C}$ at doses of $200 \mathrm{mg}$ or more daily have no effect on the incidence of the common cold, but may be beneficial in the reduction of the severity and duration of the symptoms, suggesting that vitamin $\mathrm{C}$ plays some role in the respiratory defense mechanisms. Therefore, elder patients, who have been shown to have a lowered vitamin $\mathrm{C}$ status and may therefore be more prone to infections, persons exposed to continuous oxidative stress like chronic smokers, and persons exposed to heavy 
physical exercise and/or cold environment may benefit from a moderate continuous vitamin $\mathrm{C}$ intake.

While standard doses of vitamin $\mathrm{C}$ are generally harmless, high doses can cause a number of side effects, including nausea, cramps, diarrhea and an increased risk of kidney stones [114].

Further investigations are needed in order to assess if vitamin $\mathrm{C}$ has a positive impact on preventing COVID-19.

Clinical relevance level: moderate—evidence level high

\section{Zinc}

Adequate steady intakes of zinc and vitamin $\mathrm{C}$ are essential since the body has no storage system for these two substances. Both supplements have profound effects on cellular growth and cell differentiation and have shown to be vital for the optimal functioning of the immune system. Zinc is important in cellular growth and differentiation with profound effects on antioxidant defense, collagen synthesis and the immune system. Zinc deficiency is associated with impairment of cellular mediators of innate immunity such as phagocytosis, natural killer cell activity and the generation of oxidative burst [114].

Zinc salts as lozenges have been investigated for their potential therapeutic effect on the common cold on basis of their suggested direct antiviral activity. Available trials on the effects of oral administration of zinc salts reported conflicting results, and the available evidence is inconclusive. However, a recent therapeutic trial with zinc acetate showed a significant reduction in the overall duration of symptoms and overall severity score. The discrepancies in clinical outcome with zinc salts on the common cold have recently been suggested to be due to a difference in zinc ion availability to the oral and oropharyngeal mucosal membranes in different formulations. Therefore, more studies are required, especially with zinc acetate [114].

No direct prevention effect on COVID-19 virus.

Clinical relevance level: moderate/low—evidence level low

\section{Chloroquine and Hydroxychloroquine}

Chloroquine, as well as the less toxic metabolite hydroxychloroquine, has a long history in the prevention and treatment of malaria and the therapy of certain inflammatory conditions including systemic lupus erythematosus (SLE) and rheumatoid arthritis (RA). In viruses, the two medications can inhibit $\mathrm{pH}$-dependent stages of replication. Additionally, hydroxychloroquine/chloroquine's immunomodulation is dependent on the suppression of cytokines (IL-6 and TNF- $\alpha$ ) production and dissemination.
Both substances are currently under investigation in clinical trials for pre-exposure or post-exposure prophylaxis of SARS-CoV-2 infection [115].

Chloroquine inhibits SARS-CoV-2 in vitro with a halfmaximal effective concentration. Hydroxychloroquine has a lower in vitro activity for SARS-CoV-2 compared with chloroquine after $24 \mathrm{~h}$ of growth. No high-quality evidence exists for the efficacy of chloroquine/hydroxychloroquine treatment of SARS or MERS. Secondary COVID-19 rates have shown to be reduced by hydroxychloroquine as preand post-exposure prophylaxis in patients with documented exposure to SARS-CoV-2, making it a candidate for chemoprophylaxis of secondary COVID-19 [115].

At the moment, there is a lack of clinical trial data. In the future, it could be discussed as preventive treatment approach for older patients, patients with comorbidities or patients with need for major surgery currently excluded in our guidelines for elective surgery. Clinical trials are needed to verify the validity of this approach; currently, trials for the use of hydroxychloroquine for post-exposure prophylaxis in healthcare workers are enrolling. Chloroquine and hydroxychloroquine are relatively well tolerated as demonstrated by extensive experience in patients with SLE and malaria. However, both agents can cause rare and serious adverse effects $(<10 \%)$, including hypoglycemia, QTc prolongation, neuropsychiatric effects and retinopathy [115].

Clinical relevance level: low—evidence level low

\section{Ivermectin}

Ivermectin belongs to the group of avermectins. It is administered in the case of infestation with nematodes and itch mites. The effects are due to the binding to chloride channels, which leads to paralysis and death of the parasites. The anti-parasitical drug ivermectin almost completely eliminated SARS-CoV-2 in an in vitro model within $48 \mathrm{~h}$. Further investigations in a clinical trial setting are needed to verify these results, and we do not recommend this drug for preventive approaches at date [116].

Clinical relevance level: low-evidence level low

\section{Treatment Options for Postoperative Patients Testing Positive for COVID-19}

If a patient should develop symptoms compatible with COVID-19 during the perioperative period, he should be referred immediately to a COVID-19 specialist team for further diagnostics and treatment.

Most patients with COVID-19 will be able to recover at home with symptomatic-orientated treatment, the WHO 
guidelines recommend acetaminophen (paracetamol) as first-line antipyretic [108].

If shortness of breath appears, a supply of oxygen is helpful and should be applied in a hospital setting to allow for further diagnostics and treatment response in case of clinical aggravation [117].

New treatment approaches are emerging and may be available in the future, recent data suggest promising results with nucleoside inhibitor drugs like remdesivir. While safety and pharmacokinetics have already been proven in various studies, remdesivir is currently not FDAapproved for COVID-19 treatment; clinical trials are currently enrolled to evaluate the safety and antiviral activity $[115,126]$.

Clinical relevance level: low-evidence level low

\section{Considerations on Clinical Management and Contamination Control}

Clinical management, control of patient flow and contamination control are essential to a safe working environment in the wake of the COVID-19 pandemic and have to be protocolized before restarting clinical practice.

Given our inability to use clinical symptoms or signs to evaluate actual risk of transmission, any patient (whether symptomatic or asymptomatic) must currently be considered potentially infected. This uncertainty is related to the current lack of evidence to answer the question if aerosols generated during procedures for examination or treatment are to be considered infectious [118]. The underlying assumption should be that every patient is potentially infected with COVID-19 until proven otherwise. This assumption is based on the growing community spread of COVID-19 requiring ruling out infection before treatment. Although some publications suggest that basic level PPE for protection healthcare workers (HCW) should be sufficient, it is the authors group opinion that, as screening sensitivity and specificity are limited with tests available to date, all patients and HCW should be treated as possible carrier even for low-risk procedures [119]. This article proposes a clinical circuit encompassing patient flow and contamination prevention of all clinical areas and explains the necessary steps to take for patients and HCW to perform safely in a COVID-19-free zone.

Such a circuit may be implemented easier in independent ambulatory surgery centers (ASCs) or specialty clinics than in hospitals, as the patient flow for primary care and emergency care is harder to control. Hospitals will have to adapt their structure creating COVID-19 and non-COVID19 areas to implement the proposed circuit. The guidelines we propose are based on published evidence and cover the use of personal protective equipment (PPE), surface cleaning protocols and regulation of patient flow in order to work effectively without overconcern and overuse of the limited resources available at the moment. To minimize the risk of averted contamination through asymptomatic carriers, a pre-visit questionnaire is very important (Table 3) [119, 120].

The authors group consensus recommendations regarding patient flow, HCW hygiene, PPE and decontamination are found in "Appendix 1" of this article. We reviewed current data on COVID-19 transmission in the hospital and nonhospital settings [121-124]. PPE recommendations are based on existing published data and assessments of additional operating room risk during other viral epidemics (SARS and Ebola virus disease) [125-127]. Clinical feasibility was assessed by feedback from all participants in this study.

Clinical relevance level: high-evidence level high

\section{Recommendations on Garment (PPE)}

Airborne transmission may occur when smaller respiratory particles (generally $<5 \mu \mathrm{m}$ ) circulate in the air for prolonged periods. Viral particles can be absorbed via the respiratory mucosa and potentially across the conjunctivae. Particles smaller than $10 \mu \mathrm{m}$ are most likely to penetrate deeply into the lung and cause infection. Existing data on SARS-CoV-2 regarding airborne transmission available to date suggest that social distancing is considered safe as long as a minimum distance of 1.5-2 m can be kept [128].

However, certain examinations and procedures-particularly those associated with treating or examining the face and neck - are susceptible to create aerosols by air acceleration across a fluid surface. These aerosols containing virus may linger in the air for a prolonged time and therefore bear risk of transmission independent from a physical security distance. Whether microdroplets have real infective potential depends on effective viral load and other factors and available data on SARS-CoV-2 in that sense are still inconclusive [129-132].

The authors group recommends wearing PPE during procedures where it is impossible to maintain social distancing and the HCW needs to work close to the face or mouth and until the room is cleared of aerosol (the viral clearance period) [133].

The use of masks is essential to protect general population and HCWs. Filter efficiency depends on material and sealing in classified by of FFP Level. FFP1 has a $80 \%$ clearing capacity, FFP2 up to $94 \%$ and FFP3 up to $99 \%$ including airborne $(<5$ microns) and microdroplets $(>5$ microns). Surgical masks retain only macrodroplets and have less $80 \%$ filtration efficacy [134, 135]. 
Table 3 Model for COVID-19 questionnaire to determine possible risk patients before consultations or procedures (to be performed 24-48 $\mathrm{h}$ before the appointment by phone or e-mail)

Question
Are you or any close relative a healthcare provider or work in a hospital?
Where you in contact with COVID-19 patients during the last 30 days?
Were you contaminated or tested positive for COVID 19?
Have you had any episode of fever, cough, sinusitis, anosmia, shortness of breath during the last month?
Have you traveled outside (city of healthcare facility) and surroundings during the last month? (cities or countries)
Were you non-compliant during the lockdown process?
Do you go outside without a face mask/respirator?
Do you wash your hands less than 7 times/day

If any of the questions above is answered with yes, then the patient may be at higher risk of COVID-19 infection and should be classified as high risk and submitted to screening (refer to Fig. 1)

The recommended use of PPE classed by clinical activity and the possible max. recommended reiterate use are shown in Fig. 5.

Clinical relevance level: high—evidence level high

\section{Recommendations on Decontamination and Cleaning}

Different methods can be chosen for the disinfection of hands and surfaces. Ultraviolet (UV) disinfection, hot water bath with temperature of $>56{ }^{\circ} \mathrm{C}\left(132.8{ }^{\circ} \mathrm{K}\right)$ for $30 \mathrm{~min}$, chlorine-containing disinfectants, peracetic acid or 75\% ethanol can effectively inactivate the virus [136-138].

For hand decontamination, we suggest using the rule of seven: performing hand disinfection before and after any aseptic procedure, touching a patient, changing clothes, change in clinical area, eating/drinking, bathroom use, leaving/arriving clinic.

Facial masks and FFP respirators have shown the potential of for decontamination either through short steam cycles or dry heat, but more studies are needed to confirm these recommendations [139, 140].

The authors' group recommendations on decontamination of PPE, instruments and surfaces are summarized in "Appendix 1"

Clinical relevance level: high—evidence level high

\section{Considerations for Patient Information and Patient Consent}

As discussed before, surgical/clinical outcome may be affected by a COVID-19 infection during the perioperative period $[33,34]$.
Even after implementing a clinical pathway protocol like the one proposed in this article (Fig. 1) and using an algorithm for surgical risk reduction an stratification (Fig. 3), it is the authors group opinion that specific COVID-19-related information should be transmitted to the patient and that patients should be required to sign an addendum consent form for COVID-19-associated risks known to date in the context with elective surgery.

Proposed models for a COVID-19-related patient information sheet and for a COVID-19-specific consent form are presented in "Appendix 2" and "Appendix 3" of this article.

\section{Conclusion}

The COVID-19 crisis has led to unprecedented challenges in the acute management of the crisis, and the wave only recently seems to flatten out in some countries.

The underlying tenor beneath the constant flux of newly published information, articles and case reports suggests that we have to, at least temporarily, accept a new reality for our profession and make our clinical care compatible with the challenges and threats that this pandemic will pose for the near future. According to projections for transmission dynamics of COVID-19, recurrent post-pandemic outbreaks are to be expected until herd immunity is acquired, which may take until 2024 [27].

The adaptation of surgical and procedural steps for a risk-minimizing management of potential COVID-19-positive patients seeking to undergo elective aesthetic procedures in the wake of that wave will present the next big challenge for the aesthetic surgery community. We propose a clinical algorithm to enhance patient safety in elective surgery in the context of COVID-19 and to minimize crosscontamination between healthcare workers and patients. 


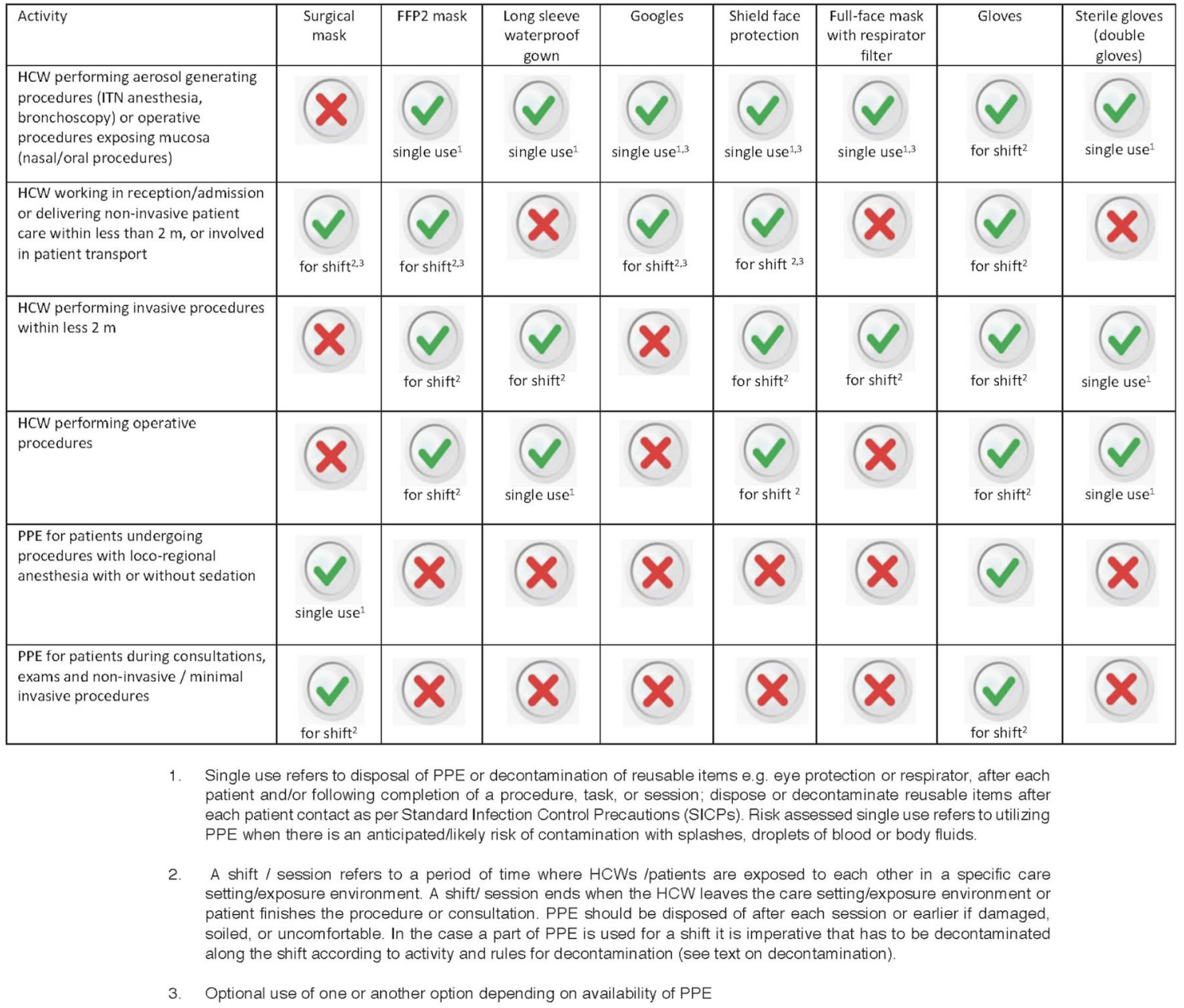

Fig. 5 PPE use

New evidence-based guidelines regarding surgical risk stratification, testing, clinical flow management/contamination management are proposed. We believe that only the continuous development and broad implementation of guidelines like the ones proposed in this paper will allow an early reintegration of all aesthetic procedures into the scope of surgical care currently performed and to prepare the elective surgical specialties better for a possible second wave of the pandemic.

As it is evident from any socioeconomic viewpoint that we cannot put elective procedures on hold forever, we believe in the need to define adequate clinical protocols to carry out elective procedures in this changed epidemiologic environment. As surgeons performing elective aesthetic procedures, we feel the obligation to weigh in the risk/ benefit ratio for our clinical decisions even stricter than for curative procedures, and this article reflects our view on that commitment toward patient safety.

We hope that the protocols and approaches presented in this article can be a valuable base for any surgical specialty looking into redefining new clinical safety guidelines for elective surgery during the post-pandemic period. As available evidence data on COVID-19 are evolving quickly, some of the recommendations in this article may change as more evidence-based data become available and testing protocols should be re-evaluated once the relative infection risk within the population or within one region becomes clearer. Some of the cited works also identified weaknesses regarding their experimental study design, and some referenced manuscripts are preprints and have not been fully peer-reviewed; therefore, we recommend following up new data available in the future.

Authors' Contributions The authors alone are responsible for the content and writing of the manuscript. Each single author contributed to acquisition and/or analysis and interpretation of data. Every single author read, reviewed and edited the manuscript. All authors contributed to the manuscript and its discussion and conclusion and approved the final manuscript. Each author agrees to be accountable for all aspects of the work. The opinions or recommendations contained herein are the private ones of the authors. 
Funding None.

Compliance with Ethical Standards

Conflict of interest All authors declare that they have no conflict of interest.

Human and Animal Rights This article does not contain any studies with human participants or animals performed by any of the authors.

Informed Consent For this type of study, informed consent is not required.

\section{Appendix 1: Recommendations on Organizational Adaptations for Scheduling, Patient Flow, Decontamination and Use of PPE in ASCs and COVID-19-Free Zones in Hospitals}

Entrance To minimize contact times and cross-contamination between $\mathrm{HCW}$ and patients different entrances should be used to separate patient and HCW flow. In case of this not being possible due to structural limitations, we recommend to space the entrance times for $\mathrm{HCW}$, patients and deliveries.

Reception/Admission To minimize exposure of seated, non-moving reception staff signaling for at least $1.5 \mathrm{~m}$ distance keeping while waiting is recommended together with physical separation (either face shield use or installed in between the patient area and receptionist) that keep the load of droplets and airborne smaller.

Visual Information and Signaling :To avoid the need for assisted guidance to the different areas of the healthcare facility we suggest creation of color-coding signage for patient guidance (e.g., colored dots on the floor, colored lines on the floor or walls and color code in each door or area entrance).

Consultation and Treatment Room Size Room size should be adequately big to allow for movement with safety distance of $1.5-2 \mathrm{~m}$ between 1 and $2 \mathrm{HCW}$ and 1 patient.

Hand Sanitizer There should be a hand sanitizer holder in each entrance and also in each area of the ASC that permits sanitizing the hands in between areas.

Shoe Covers/Surgical Mask/Gloves We recommend dispensers (automatic or not) at each entrance.

HCW Changing Room HCW should change into scrubs and store their street clothes in a bag for clothes tagged with the name. If there are more than $10 \mathrm{HCW}$, the user time flow for changing room use should spaced.

$P P E$ There should be a separated area in changing room for dispensing specific PPE and also a checklist for PPE.

\section{Adaptation of Agenda}

Sufficient spacing between appointments and procedures is necessary to allow for distancing between patients and leave time for decontamination.

1. Consultations: We recommend spacing of $30 \mathrm{~min}$ in between consultations to allow patient flow and cleaning. If more than one doctors are doing consultation on same day than there should be alternated spacing.

2. Medical/Aesthetic Procedures (e.g., injectables): We recommend spacing of $40 \mathrm{~min}$

3. Surgeries: We recommend spacing of $90 \mathrm{~min}$

\section{Adaptation of Patient Flow}

As many corridors in ASCs or specialty clinics do not allow to keep distance of min $1.5 \mathrm{~m}$ between 2 people passing, patient flow should be managed by spacing scheduling to minimize inter patient contact.

\section{Adaptation of Schedule}

Reception should perform the pre-questionnaire to decide the suitability of the patient to come for consultation or procedure. If all answers are No, the patient qualifies to come to the clinic (Table 2). The patient should be advised that they should come alone (exception only for surgeries that require a companion for post-anesthesia care)

Patient arrival (assuming the pre-questionnaire was answered with NO)

1. Before entering clinic $=$ hand disinfection with alcohol gel, put shoe protection and wear mask and gloves. If possible, patients should bring their own mask

2. Entering and keeping $1.5 \mathrm{~m}$ distance from the reception waiting for instructions

3. Infrared temperature check and asked if hand disinfection has been performed.

4. After check-in/admission, receptionist will direct a color line/CODE to follow

\section{Patient consultation and treatment}

1. Consultations

1. Patient will follow color codes to the referred office/ treatment room

2. During consultation $1.5 \mathrm{~m}$ distance should be kept, patient and HCW wear masks, if closer approach is needed PPE (Fig. 5) should be worn. 
3. HCW and patient disinfect the hands upon entering the office/treatment room

4. In cases where patients need to be examined naked a plastic bag should be provided to put clothes inside during consultation.

5. Patient should repeat disinfection of the hands after getting dressed.

6. HCW explains the use of every item in the prescription.

7. Prescriptions and/or medications will be collected in reception area.

8. Patient should be redirected to reception area; in case the patient came for multiple purposes such as pre-op appointment, HCW should advise the reception that the consultation is over and that the patient will be redirected to another area.

9. Hands of patient and doctor/aesthetician should be disinfected upon leaving the office

2. Aesthetic non-surgical procedures

1. Patient will follow color codes to the referred office/ treatment room

2. During consultation/treatment $1.5 \mathrm{~m}$ distance should be kept, patient and HCW wear masks, if closer approach is needed PPE (Fig. 5) should be worn

3. HCW and patient disinfect the hands upon entering the office/treatment room

4. Hand disinfection should be done upon entering and leaving the room

5. Used instruments should be put in a plastic sealable bag for transport to decontamination area

6. It is not allowed to reuse or any material or to bring any material from outside clinic

7. In case of body treatments, a plastic drape will be put under the patient and the therapist needs to wear a FFP2 mask, gown and gloves (Fig. 5).

8. Prescription and orientations will be printed in reception and sent by mail or telemedicine apps, meds and creams will be given to the patients in a bag with printed prescription inside. Explanations will be given by the $\mathrm{HCW}$ in the room before patient leaves.

9. Patient will follow back the color lines to reception

3. Surgical patient

1. Admission-Patient and max 1 companion will follow color codes/signing to preoperative area/ ward.

1. Both will disinfect the hands upon arrival and when leave the room.

2. Room preparation-A kit for each patient should be left in the bed with a surgical mask and gloves added. Patient clothes should be put in a plastic bag while in surgery.

3. After taking off the clothes and putting them in a plastic bag the patient should pull the hair with elastic bands and wear a hair cap, disposable gown and foot protection.

4. Patient marking - if applicable, surgeon should be alone during marking and wearing PPE (Fig. 5).

5. Transport to OR-HCW should be wearing PPE, while transporting the patient to the OR (Fig. 5)

2. Surgery

1. All HCWs need to disinfect the hands before and after changing areas between ORs, induction preparation areas and recovery area.

2. Anesthesia induction should be performed with a minimum number of HCWs necessary in the OR when intubation is required and a plastic drape should be placed over the head and in chest isolating the intubation area, anesthetist should wear double gloves and PPE [138].

3. Instruments used during anesthesia and surgery should be sealed in a bag for transporting them to sterilization room.

4. If surgery is performed on the body, a plastic drape should be put under the head and another plastic drape should be placed above the chest to create a tent isolating the face area. For sedation procedures, surgical field/drape may be adapted to cover oral/nasal cavities. (except for eyelid procedures)

5. After surgery is finished, all the bags should be closed to transport reusable instruments.

6. All HCWs should stay at least $1.5 \mathrm{~m}$ apart while taking off non reusable PPE and placing it in protected bins.

7. Hand disinfection should be done after surgery and after all reusable PPE has been placed in a plastic box inside OR for decontamination.

8. Not more than one patient should stay in postoperative care area.

9. After determined time, the patient will be transported by $\mathrm{HCW}$ wearing PPE to the room

3. Discharge of patient: At discharge, the patient should be discharged from its room directly without necessity to pass by reception. All instructions and medications/prescriptions should be available at time of discharge in the patients room. 


\section{Reception}

1. Office administration

1. Mail and packages:

Packages should be delivered at the door and not enter in the clinic.

The packages and mail should be put in a closed box to be open by the receptionist in a proper time when the clinic has no patient flow and proper disinfection can be performed

2. Laboratory and pathology:

1. All samples for laboratory analysis and pathology will be kept each with the request inside a sealed bag and all bags inside a closed box.

2. The collection should be booked for the end of day and only once a day.

3. Receptionist should place all small bags in a big sealed bag

4. Receptionist should give the sealed bag to the collector that should be wearing gloves and mask.

3. Patient administration:

1. Prescriptions

1. Prescriptions: The creams/medications will be handled by the receptionists and put in a bag along with the prescription printed for the aesthetic/consultation patients to take home. For surgical patients, the bag should be left in the room before patient leaves.

2. Payments: Payment should be done in reception preferably with contactless or with card. If not, money and change should be passed on by putting it on the counter, avoid touching of hands when handling money. (Admins staff needs to change or disinfect the gloves after handling money.) In surgical cases, the payment should be ideally done in full by money transfer before surgery, or upon arrival in the facility to avoid that the patient needs to return to reception to pay after surgery.

3. New appointments should be primarily given by e-mail/phone/WhatsApp to avoid patient congestion at reception.

\section{Recommendations on Disinfection and Decontamination}

PPE_Full-face masks, Googles and Face Shields can be disinfected with ethanol $60-80 \%$ and chlorine-containing disinfectants and this should be done in end of each shift.

Masks-Facial masks and FFP respirators have shown the potential of for decontamination through either short steam cycles or dry heat, but more studies are needed to confirm these recommendations [139, 140].

Instruments-They should be put in a sealed bag for transport from OR to sterilization room and sterilized following standard facility protocols.

Surfaces-Requirements for surface decontamination depend on the procedures performed in the area, the potential grade of contamination during the procedure/consultation and the frequency of use.

We recommend classifying clinical areas in levels of decontamination:

1. Low level: Regular cleaning with no special recommendation

2. Moderate level: Reception, waiting room, bathrooms, patient rooms and consultation rooms should be cleaned with broad-spectrum enzymatic detergent once a day and with alcohol (ethanol 60-80\%) or similar surface agent after every patient use.

3. High level: Treatment rooms, ORs and recovery area or any area where invasive procedures are done, should be decontaminated using high-to-low surface cleaning with specific enzymatic detergents providing broadspectrum coverage* for bacteria, fungus, spores and virus (hydro- and lipophilic), e.g., Aniosyme (Anios, France).

UVC light decontamination is another possible procedure if available at the facility.

*(Approved broad disinfectants according CDC 2020: chloride solutions, ethanol $60-80 \%$, peracetic acid, hydrogen peroxide, iodophors or combinations: ethanol + quaternary ammonium)

We recommend preparation of the facility before reopening with Environmental Protection Agency (EPA)-approved bactericidal and virucidal agent (e.g., Sporicidin) through a certified disinfecting company. Air conditioners should be disinfected and cleaned through a certified company. Ductbased air conditioners that distribute and share air between different clinical sections should not be used without adequate decontamination measures (UVC, ionization, HEPA filters, etc.)

Disinfection certificate should be displayed on reception. 


\section{Appendix 2: Proposed Information Form for Elective Surgery During COVID-19}

The healthcare workers of (Unit/ Department) are strictly following the guidelines and regulations of local health authorities and international societies concerning the measures to be taken before, during, and after the surgical intervention with respect to the COVID-19 outbreak. Please note that many of these guidelines are subject to constant change and that we may adapt them accordingly. Most recent educational material concerning the hygiene and social distancing measures are published on the World Health Organization (WHO) Web site.

Extended hygiene measures are applied to the entire personnel, facility and equipment used for your treatment. In particular, disinfection of hands and decontamination of all relevant surfaces are carried out continuously and between each single patient contact. Disposable personal protective equipment (PPE) such as masks, face shields and gloves is used for our team and patients whenever applicable and appropriate. Any signs of COVID-19 relevant symptoms in the healthcare team, such as cough or fever, lead to temporary exclusion from the treatment team and are subject to further investigation. All of our healthcare workers get tested periodically. Most of these measures form a part of standard precautions to reduce transmission of nosocomial infections and have been in place already before the COVID-19 outbreak. Novel measures are therefore complementing and not replacing already established clinical practices.

You may be subject to a telephone screening $24 \mathrm{~h}$ prior to the surgery, and during your clinical stay, separation from other patients in the facility will be pursued whenever feasible. Furthermore, the body temperatures of patients patient or any accompanying person will be checked upon admission.

Preoperative diagnostic testing for COVID-19 may be performed if you undergo surgical procedures, and you will be asked to report us any relevant symptoms regarding the COVID-19 infection. You should notify the healthcare provider if you are a subject to any increased risks (e.g., immunosuppressed patients). As these precautions are also incorporated in our visiting policies, currently only 1 accompanying person per patient is admitted.

Except in cases of emergency, we are currently only attending patients with no COVID-19-related symptoms to reduce the risk of transmission for patients and healthcare workers.

Please note that there may be amendments in perioperative anesthesia protocols which may also reflect in the type of anesthesia used and in the preoperative tests being ordered for your procedures. As always, you will be able to discuss all options with your anesthetist during the preoperative consultation.

To our best knowledge of currently published data, the risk of COVID-19 infection during your elective treatment can be considered as low if all the necessary precautions are taken; however, it cannot be excluded.

\section{Appendix 3: SARS-COV-2 (COVID-19) Addendum Consent Surgical and Therapeutic Procedures}

There is currently no specific treatment for SARS-CoV-2 coronavirus in patients with suspected or confirmed COVID-19; however, the information could change rapidly due to the results or several studies in progress to stop the virus. In this exceptional circumstance derived from the COVID-19 pandemic, given the high risk of infectious transmission of the virus in unavoidable physical proximity to the patient for medical treatment, it is NOT possible to endure a NULL RISK of transmission of COVID-19, even with all the means of protection available, in addition to those already established. Currently, the biological risk of COVID-19 is still NOT perfectly known from a scientific point of view. There is currently no vaccine to prevent COVID-19, nor is there any specific treatment, so curing will depend on the signs and symptoms, whether they are mild, moderate or severe, including pneumonia, acute respiratory distress syndrome (ARDS), sepsis and septic shock, as well as the clinical manifestations that occur. The indications and actions suggested by the corresponding medical team will be interpreted and applied in an individualized manner for each patient, in terms indicated in the previous paragraph, with the prescriptive freedom of each health professional remaining for the benefit of the patient. Particular circumstances of patient conditions with a high risk of transmission of COVID-19, with serious consequences for his/her health include people: over 60, pregnant or immediately postpartum, or diagnosed with high blood pressure, diabetes mellitus, chronic heart of lung disease, immunosuppression (acquired or provoked), or renal or hepatic failure. In this act, the patient acknowledges that with being the subject of medical attention, whether by means of a surgical and/or therapeutic procedure, there is no guaranteed zero risk of acquiring the SARS-COV-2 (COVID-19) virus during or after the act, in the recovery phase. In case of acquisition of the virus shortly before, during or after treatment, medical attention or surgical procedure, the clinical evolution may be different and/or the possibility for the development of possible perioperative complications including death may be significantly higher than in COVID-negative patients. 
The patient understands that in spite of numerous and diligent hygiene and safety measures, medical-surgical care and outpatient consultations give rise to possibilities of contagion which he or she understands and expressly accepts. The patient understands and gives consent to perioperative test of COVID-19, whether viral charge test (PCR) or antibody test.

\section{Date}

Signature of patient Signature of the healthcare provider

\section{References}

1. Wang C, Horby PW, Hayden FG, Gao GFJTL (2020) A novel coronavirus outbreak of global health concern. Lancet 395:470-473

2. WHO Novel Coronavirus (COVID-19) Dashboard. https://www. who.int/. Last Accessed 15 Apr 2020

3. Sohrabi C, Alsafi Z, O'Neill N et al (2020) World Health Organization declares global emergency: a review of the 2019 novel coronavirus (COVID-19). Int J Surg 76:71-76. https://doi. org/10.1016/j.ijsu.2020.02.034

4. Bai Y, Yao L, Wei T et al (2020) Presumed asymptomatic carrier transmission of COVID-19. JAMA 323(14):1406-1407. https://doi.org/10.1001/jama.2020.2565

5. Phan LT, Nguyen TV, Luong QC et al (2020) Importation and human-to-human transmission of a novel coronavirus in Vietnam. N Engl J Med 382(9):872-874. https://doi.org/10.1056/ NEJMc2001272

6. Li YK, Peng S, Li LQ et al (2020) Clinical and transmission characteristics of Covid-19-a retrospective study of 25 cases from a single thoracic surgery department. Curr Med Sci. https:// doi.org/10.1007/s11596-020-2176-2

7. Brücher B, Nigri G, Tinelli A et al (2020) COVID-19: pandemic surgery guidance. Open. https://doi.org/10.1051/fopen/2020002

8. Wu D, Wu T, Liu Q, Yang Z (2020) The SARS-CoV-2 outbreak: what we know. IJID. https://doi.org/10.1016/j.ijid.2020. 03.004

9. Salehi S, Abedi A, Balakrishnan S, Gholamrezanezhad A (2020) Coronavirus disease 2019 (COVID-19): a systematic review of imaging findings in 919 patients. AJR 215:1-7

10. Aghagoli G, Gallo Marin B, Soliman LB, Sellke FW (2020) Cardiac involvement in COVID-19 patients: risk factors, predictors, and complications: a review. J Card Surg. https://doi. org/10.1111/jocs. 14538

11. Wu C, Chen X, Cai Y et al (2020) Risk factors associated with acute respiratory distress syndrome and death in patients with coronavirus disease 2019 pneumonia in Wuhan, China. Intern Med. https://doi.org/10.1001/jamainternmed.2020.0994

12. Ioannidis JPA, Axfors C, Contopoulos-Ioannidis DG (2020) Population-level COVID-19 mortality risk for non-elderly individuals overall and for non-elderly individuals without underlying diseases in pandemic epicenters. medRxiv 20054361

13. Rajan N, Joshi GP (2020) The COVID-19: role of ambulatory surgery facilities in this global pandemic. Anesth Analg. https:// doi.org/10.1213/ane.0000000000004847
14. Iacobucci G (2020) Covid-19: all non-urgent elective surgery is suspended for at least three months in England. BMJ 18(368):m1106. https://doi.org/10.1136/bmj.m1106

15. COVID-19: recommendations for management of elective surgical procedures in aesthetic surgery-ISAPS. https://www. isaps.org/covid-19/covid-19-recommendations-for-

management-of-elective-surgical-procedures-in-aestheticsurgery/. Last Accessed 15 Apr 2020

16. COVID19-E(A)SAPS recommendations for aesthetic surgery. https://www.easaps.org/?p=3001. Last Accessed 15 Apr 2020

17. ASPS Guidance Regarding Elective and Non-Essential Patient Care. https://www.plasticsurgery.org/for-medical-professionals/ covid19-member-resources\#statement. Last Accessed $15 \mathrm{Apr}$ 2020

18. Correia MITD, Ramos RF, Bahten LCV (2020) The surgeons and the COVID-19 pandemic. Rev Col Bras Cir 47:e20202536. https://doi.org/10.1590/0100-6991e-20202536

19. Cohen SL, Liu G, Abrao M, Smart N, Heniford T (2020) Perspectives on surgery in the time of COVID-19: safety first. J Minim Invasive Gynecol. https://doi.org/10.1016/j.jmig.2020. 04.003

20. Giulio M, Maggioni D, Montroni I et al (2020) Being a doctor will never be the same after the COVID-19 pandemic. Am J Med. https://doi.org/10.1016/j.amjmed.2020.03.003

21. Prem K, Liu Y, Russell TW et al (2020) The effect of control strategies to reduce social mixing on outcomes of the COVID-19 epidemic in Wuhan, China: a modelling study. Lancet Public Health. https://doi.org/10.1016/S2468-2667(20)30073-6

22. Leung K, Wu JT, Liu D, Leung GM (2020) First-wave COVID19 transmissibility and severity in China outside Hubei after control measures, and second-wave scenario planning: a modelling impact assessment. Lancet. https://doi.org/10.1016/s01406736(20)30746-7

23. Xu S, Li Y (2020) Beware of the second wave of COVID-19. Lancet. https://doi.org/10.1016/s0140-6736(20)30845-x

24. American College of Surgeons and American Society of Anesthesiologists: Joint Statement: Roadmap for Resuming Elective Surgery after COVID-19 Pandemic. https://www.facs.org/covid19/clinical-guidance/roadmap-elective-surgery. Last Accessed 15 Apr 2020

25. COVID-19 projections assuming full social distancing through May 2020 Institute for Health Metrics and Evaluation 2301 Fifth Ave., Suite 600 Seattle, WA 98121. https://covid19.healthdata. org/spain. Last Accessed 15 Apr 2020

26. Legido-Quigley H, Mateos-García JT, Campos VR, Gea-Sánchez M, Muntaner C, McKee M (2020) The resilience of the Spanish health system against the COVID-19 pandemic. Lancet Public Health. https://doi.org/10.1016/s2468-2667(20)30060-8

27. Xiao AT, Tong YX, Zhang S (2020) False-negative of RT-PCR and prolonged nucleic acid conversion in COVID-19: rather than recurrence. J Med Virol. https://doi.org/10.1002/jmv.25855

28. Mungmunpuntipantip R, Wiwanitkit V (2020) Uncertainty in using chest computed tomography in early coronavirus disease (COVID-19). Can J Anaesth. https://doi.org/10.1007/s12630020-01639-y

29. Cassaniti I, Novazzi F, Giardina F et al (2020) Members of the San Matteo Pavia COVID-19 task force. Performance of VivaDiag COVID-19 IgM/IgG rapid test is inadequate for diagnosis of COVID-19 in acute patients referring to emergency room department. J Med Virol. https://doi.org/10.1002/jmv.25800

30. Rothe C, Schunk M, Sothmann P et al (2020) Transmission of 2019-nCoV infection from an asymptomatic contact in Germany. N Engl J Med. https://doi.org/10.1056/NEJMc2001468

31. Chen WH, Strych U, Hotez PJ, Bottazzi ME (2020) The SARSCoV-2 vaccine pipeline: an overview. Curr Trop Med Rep. https://doi.org/10.1007/s40475-020-00201-6 
32. Kissler SM, Tedijanto C, Goldstein E, Grad YH, Lipsitch M (2020) Projecting the transmission dynamics of SARS-CoV-2 through the postpandemic period. Science. https://doi.org/10. 1126/science.abb5793

33. Aminian A, Safari S, Jahromi RA, Ghorbani M, Delaney CP (2020) COVID-19 outbreak and surgical practice: unexpected fatality in perioperative period. Ann Surg. https://doi.org/10. 1101/2020.04.05.20054361

34. Lei S, Jiang F, Su W et al (2020) Clinical characteristics and outcomes of patients undergoing surgeries during the incubation period of COVID-19 infection. EClinicalMedicine. https://doi. org/10.1016/j.eclinm.2020.100331

35. Mofid MM, Teitelbaum S, Suissa D, Ramirez-Montañana A, Astarita DC, Mendieta C, Singer R (2017) Report on mortality from gluteal fat grafting: recommendations from the ASERF task force. Aesth Surg J 37(7):796-806

36. Khavanin N, Jordan SW, Vieira BL et al (2015) Combining abdominal and cosmetic breast surgery does not increase shortterm complication rates: a comparison of each individual procedure and pretreatment risk stratification tool. Aesth Surg J 35(8):999-1006

37. Kaoutzanis C, Gupta V, Winocour J et al (2017) Cosmetic liposuction: preoperative risk factors, major complication rates, and safety of combined procedures. Aesth Surg J 37(6):680-694

38. Simon S, Thaller SR, Nathan N (2006) Abdominoplasty combined with additional surgery: a safety issue. Aesth Surg J 26(4):413-416

39. Hardy KL, Davis KE, Constantine RS et al (2014) The impact of operative time on complications after plastic surgery: a multivariate regression analysis of 1753 cases. Aesth Surg J 34(4):614-622

40. Kamps BS, Hoffmann C (2020) COVID reference. Steinhauser Verlag

41. Uppal V, Sondekoppam RV, Lobo CA, Kolli S, Kalagara HKP (2020) Practice recommendations on neuraxial anesthesia and peripheral nerve blocks during the COVID-19 pandemic. A joint statement by the American society of regional anesthesia and pain medicine (ASRA) and European Society of regional Anesthesia and Pain Therapy (ESRA). https://www.asra.com/ page/2905/practice-recommendations-on-neuraxial-anesthesiaand-peripheral-nerve-blocks-during-covid-19-pandemic. Last Accessed 15 Apr 2020

42. Lei S, Jiang F, Wating S et al (2020) Clinical characteristics and outcomes of patients undergoing surgeries during the incubation period of COVID-19 infection. Elsevier Clin Med. https://doi. org/10.1016/j.eclinm.2020.100331

43. Cabrera SFD, Clavel LLM, Roman MAH (2020) COVID-19. Vision de Anestesiologo. revista cubana de Cardiología y Cirugía cardiovascular. 26(1), ISSN: 1561-2937

44. ASA Physical Status Classification System. American Society of Anesthesiologists (Approved by the House of Delegates on October 15, 2014 and last amended on October 23, 2019. https:// asahq.org/standars-and-guidelines/asa-physical-statusclassification-system. Last Accessed 15 Apr 2020

45. Rajan N, Joshi GP (2020) The Covid-19: role of ambulatory surgery facilities in this global pandemic. Anesth Analg J. https://doi.org/10.1213/ane.0000000000004847

46. Liang T, Handbook of COVID-19 prevention and treatment. The First Affiliated Hospital. Zhejiang University School of Medicine. Compiled According to Clinical Experience

47. Diagnosis and Treatment Protocol for Novel Coronavirus Pneumonia Released by The General Office of National Health Commission. Office of State Traditional Chinese Medicine. TCM Administration. March 3, 2020. http://busan.chinaconsulate.org/chn/zt/4/P020200310548447287942.pdf
48. Recalti S (2020) Cutaneous manifestation in COVID-19: a first perspective. J Eur Acad Dermatol Venerol. Department of Dermatology, ASTT Lecco, Alessandro Manzoni Hospital, European Academy of Dermatology and Venereology. https:// doi.org/10.1111/jdv.16387

49. Ritesh Maharaja 9th March 2020. King's College Hospital NHS. Critical Care-Evidence Summary Clinical Management of COVID-19. https://www.kch.nhs.uk. https://wspidsoc.kenes. com/wp-content/uploads/sites/95/2020/03/KCC-covid19evidence-summary.pdf. Last Accessed 15 Apr 2020

50. Chen R, Zhang Y, Huang L, Cheng B-H, Xia Z, Meng Q (2020) Safety and efficacy of different anesthetic regimens for parturients with Covid-19 undergoing Cesarean delivery: a case of 17 patients. Can J Anesth. https://doi.org/10.1007/s12630-02001630-7

51. Wen X, Li Y (2020) Letter to the editor. Anesthesia procedure of emergency operation for patients with suspected or confirmed COVID-19. Surg Infect. https://doi.org/10.1089/sur.2020.040

52. Greenland JR, Michelob MD, Wang L, London MJ (2020) COVID-19 implications for preoperative and critical care physician. Anesthesiology. https://doi.org/10.1097/aln. 0000000000003303

53. Peng PWH, Ho P-L, Hota SS (2020) Outbreak of a new coronavirus: what anesthetist should know. Editorial. Br J Anaest. https://doi.org/10.1016/j.bja.2020.02.008

54. Chen Z, Hu J, Zhang Z et al (2020) Efficacy of hydroxychloroquine in patient with COVID-19: results of randomized trial. https://doi.org/10.1101/2020.03.22.20040758

55. Terapia medica COVID 19 revisión de marzo 27 2020. en sistema sociosanitario Regiones Lombardia. ASST papa Giovanni XXIII. www.asst-pg23.it/

56. Barbosa J, Kaitis D, Freedman R, Le K, Lin X (2020) Clinical outcomes of hydsroxicloroquina in hospitalized patients with COVID-19: a quasi-randomized comparative study. N Engl J Med. Manuscript ID 20-08882

57. Chen X, Liu Y, Gong Y et al (2020) Perioperative management of patients infected with the novel coronavirus. Recommendation from the joint task force of Chinese Society of Anesthesiology and the Chinese Association of Anesthesiologist. Anesthesiology. https://doi.org/10.1097/aln.000000000000331

58. Balibrea J, Badia JM, Perez IR et al (2020) Manejo quirúrgico de pacientes con infección por COVID-19. recomendaciones de la Asociación Española de cirujanos. Cirugía Española. https:// doi.org/10.1016/j.ciresp.2020.03.001

59. Iberoamerica C (2020) El valor de Dimero-d asociado a la gravedad de los pacientes con la COVID-19. Huang Lancet 395(10223):497-506. Tang J Thromb Haemost 2020. https://doi. org/10.1111/jth.14768. Wang Jama 2020. https://doi.org/10. 1001/jama.2020.1585

60. Recomendaciones Institucionales. Documento De Posicionamiento de la SEIMC sobre el Diagnostico Microbiologico de COVID-19. Sociedad Española De Enfermedades Infecciosas. https://seimc.org/contenidos/documentoscientificos/ recomendaciones/seimc-rc-2020-posicionamiento_SEIMC_ diagnostico_microbiologico_COVID19.pdf

61. Documento Tecnico Manejo clinico del COVID-19 en Atencion Hospitalaria. Ministerio de Salud. Gobierno de España. 19 marzo 2020. https://mscbs.gob.es/profesionales/saludPublica/ ccayes/alertasActual/nCov-china/documentos/. Last Accessed 15 Apr 2020

62. Trujillo A (2020) Letter to the Editor. Response to Wen and Li. Anesthesia procedure of emergency operation for patient suspected of confirmed COVID-19. Surg Infect. https://doi.org/10. 1089/sur.2020.088 
63. Sanders JM, Monogue ML, Jodlowski TZ, Cutrell JB (2019) Pharmacologic treatments for coronavirus disease 2019 (covid19). JAMA. https://doi.org/10.1001/jama.2020.6019

64. Russell CD, Millar JE, Baillie JK (2020) Clinical evidence does not support corticosteroids treatment for 2019-nCoV lung injury. Lancet 395(10223):473-475. https://doi.org/10.1016/s01406736(20)30317-2

65. Zhong Q, Liu YY, Luo Q et al (2020) Spinal anesthesia for patients with coronavirus disease 2019 and possible transmission rates in anesthetists: retrospective, single-centre, observational cohort study. Br J Anaesth. https://doi.org/10.1016/jba. 2020.03.007

66. Aliste, Altermatt F, Atton R, Bravo D, Layera S, Miranda P, Pesce Italo. Recomendaciones para la ejecucion de anestesia regional no obstétrica en perioperatorio de pacientes COVID-19. grupo de trabajo comité Anestesia Regional de la sociedad de Anestesióloga de Chile. revista chilena anestesiologia 2020. https://doi.org/10.25237/revchilanestv49n03.08

67. Lie S, Wong CW, Wong LT, Wong TGL, Chong SY (2020) Practical consideration for performing regional anesthesia: lessons learned from COVID-19 pandemic. Can J Anesth

68. The Third American Society of Regional Anesthesia and Pain Medicine Practice Advisory on Local Anesthetics Systemic toxicity (2018) Executive summary 2017. Reg Anesth Pain Med 43:113-123. Guidelines of the American Society of Regional Anesthesia and Pain Medicine. http://www.asra.com/content/ documents/asra_last_checklist_2018.pdf. https://doi.org/10. 1007/s12630-020-01637-0marzo2020

69. Alhazzani W, Hylander M, Arabi YM et al (2020) European society of intensive care medicine and the society of critical care medicine 2020. Surviving Sepsis Campaign: Guidelines on the Management of critical Ill Adults with Coronavirus disease (covid-19). Intensive Care Med. https://doi.org/10.1007/s00134020-06022-5

70. Sorbello M, El-Boghdadly K, DiGiacinto IR et al (2020) On behalf of Societa Italiana di anestesia analgesia rianimazione e terapia intensiva (SIAARTI) Airway Research Group, and The European Airway Management Society. The Italian Coronavirus Disease 2019 outbreak: recommendations from Clinical Practice. Anesthesia. https://doi.org/10.1111/anae.15049

71. Anesthesia and caring for patients during the COVID-19 outbreak. Australian Society of Anesthetists, 3 Apr 2020. https:// asa.org.au/covid-19-updates

72. Sanz JG (2020) Protocolo de Ingreso y Manejo en UCI de Pacientes con COVID-19. Servicio de Medicina Intensiva Hospital Universitario Pueta De Hierro. Comunidad de Madrid. España 26 March 2020. Jgsanz@me.com

73. Cook TM, El-Bogdadly K, Mcguire B, McNarry AF, Patel A, Higgs A (2020) Consensus guidelines for managing the airways in patients with COVID-19. Guidelines form the Difficult Airway Society, the association of anesthetist the Intensive care Society, the Faculty of Intensive Care Medicine and Royal College of anaesthetists. https://doi.org/10.1111/anae.15054

74. Meng L, Qiu H, Wan L et al (2020) Intubation and ventilation amid the COVID-19 Outbreak. Wuhan's experience. Anesthesiology. https://doi.org/10.1097/aln.0000000000003296

75. Minnejad R, Salimi A, Saeidi M (2020) Lidocaine during intubation and extubation in patients with coronavirus decease (covid-19). Can J Anesth. https://doi.org/10.1007/s12630-02001627-2

76. Zueco L, Levy N, Ketchandji D et al (2020) Recommendations for airway management in a patient with suspected coronavirus (COVID-19) infection, from anesthesia patient safety foundation. February 12 2020. https://apsf.org/news-updates/ perioperative-consideration-for-the-2019-novel-coronaviruscovid-19/
77. Kowalski LP, Sanabria A, Ridge JA et al (2020) Covid-19 pandemic: effects and evidence-based recommendations for otolaryngology and head and neck surgery practice. https://doi. org/10.1002/hed.26164

78. Narvaez GO, Guerero CA (2009) Actualización en Fundamentos Bioquímicos de la inmunotoxicologia de los opiaceos. Universidad Nacional de Bogota Colombia. rey.Fac.Med. 57(3)

79. Feldman J, Loeb R (2020) Anesthesia Machine use, protection, and decontamination during the COVID-19 pandemic. Protecting the anesthesia Station-. Anesthesia patient Safety Foundation. Based on COVID-19 guidelines from ASA, APSF. April 16, 2020. https://apsf.org/faq-on-anesthesia-machine-use-anddecontamination-during-the-covid-19-pandemic/. Last Accessed 15 Apr 2020

80. Laboratory testing for novel coronavirus (2019-nCoV) in suspected human cases. Interim Guidance. Geneva: World Health Organization (2020). https://www.who.int/publications-detail/ laboratory-testing-for-2019-novel-coronavirus-in-suspectedhuman-cases-20200117. Last Accessed 15 Apr 2020

81. Udugama B, Kadhiresan P, Kozlowski HN et al (2020) Diagnosing COVID-19: the disease and tools for detection. ACS Nano

82. Okba NMA, Müller MA, Li W, Wang C et al (2020) Severe acute respiratory syndrome coronavirus 2-specific antibody responses in coronavirus disease 2019 patients. Emerg Infect Dis 26,7

83. Green K, Winter A, Dickinson R et al (2020) What tests could potentially be used for the screening, diagnosis and monitoring of COVID-19 and what are their advantages and disadvantages? https://www.cebm.net/wp-content/uploads/2020/04/

CurrentCOVIDTests_descriptions-FINAL.pdf. Last Accessed 15 Apr 2020

84. Here's How Coronavirus Tests Work-and Who Offers Them. https://www.scientificamerican.com/article/heres-how-

coronavirus-tests-work-and-who-offers-them/. Last Accessed 15 Apr 2020

85. Wölfel R, Corman VM, Guggemos W et al (2020) Virological assessment of hospitalized patients with COVID-2019. Nature

86. Xiao S-Y, Wu Y, Li J (2020) Evolving status of the 2019 novel coronavirus infections: proposal of conventional serologic assays for disease diagnostics and infection monitoring. J Med Virol 2020:1-4

87. To KK, Tsang OT, Leung WS et al (2020) Temporal profiles of viral load in posterior oropharyngeal saliva samples and serum antibody responses during infection by SARS-CoV-2: an observational cohort study. Lancet Infect Dis. https://doi.org/10. 1016/S1473-3099(20)30196-1

88. Vashist SK (2020) In vitro diagnostic assays for COVID-19: recent advances and emerging trends. Diagnostics (Basel) 10(4):202

89. Corman VM, Landt O, Kaiser M et al (2020) Detection of 2019 novel coronavirus $(2019-\mathrm{nCoV})$ by real-time RT-PCR. Eurosurveill 25:2000045

90. Meyer B, Drosten C, Müller MA (2014) Serological assays for emerging coronaviruses: challenges and pitfalls. Virus Res 19(194): 175-183

91. Huang P, Liu T, Huang L et al (2020) Use of chest CT in combination with negative RT-PCR assay for the 2019 novel coronavirus but high clinical suspicion. Radiology 295:22-23

92. Li Q et al (2020) Early transmission dynamics in Wuhan, China, of novel coronavirus-infected pneumonia. $\mathrm{N}$ Engl $\mathrm{J}$ Med 382:1199-1207

93. He X, Lau EHY, Wu P et al (2020) Temporal dynamics in viral shedding and transmissibility of COVID-19. Nat Med. https:// doi.org/10.1038/s41591-020-0869-5 
94. What Immunity to COVID-19 Really Means. https://www. scientificamerican.com/article/what-immunity-to-covid-19really-means/

95. http://www.centerforhealthsecurity.org/resources/COVID-19/ serology/Serology-based-tests-for-COVID-19.html. Last Accessed 15 Apr 2020

96. Tang Y-W, Schmitz JE, Persing DH et al (2020) The laboratory diagnosis of COVID-19 infection: current issues and challenges. J Clin Microbiol. https://doi.org/10.1128/JCM.00512-20

97. Sun ZF, Meng XJ (2004) Antigenic cross-reactivity between the nucleocapsid protein of severe acute respiratory syndrome (SARS) coronavirus and polyclonal antisera of antigenic Group I animal corona viruses: implication for SARS diagnosis. J Clin Microbiol 42(5):2351-2352

98. Clinical guide for the management of critical care patient during the coronavirus pandemic. Speciality guides for patient management during the coronavirus pandemic. NHS 16 March 2020. https://www.england.nhs.uk/coronavirus/secondary-care/otherresources/specialty-guides/. Last Accessed 15 Apr 2020

99. Chen R, Zhang Y, Huang L, Cheng BH, Xia ZY, Meng QT (2020) Safety and efficacy of different anesthetic regimens for parturients with COVID-19 undergoing Cesarean delivery: a case series of 17 patients. Can J Anaesth. https://doi.org/10. 1007/s12630-020-01630-7

100. Keeley AJ, Evans C, Colton H et al (2020) Roll-out of SARSCoV-2 testing for healthcare workers at a large NHS Foundation Trust in the United Kingdom, March 2020. Euro Surveill 25(14):2000433

101. Torrance HD, Pearse RM, O’Dwyer MJ (2016) Does major surgery induce immune suppression and increase the risk of postoperative infection? Curr Opin Anaesth 29(3):376-383

102. Torrance HDT, Longbottom ER, Vivian ME et al (2018) Postoperative immune suppression is mediated via reversible, Interleukin-10 dependent pathways in circulating monocytes following major abdominal surgery. PLoS ONE 13(9):e0203795

103. Xu K, Cai H, Shen Y et al (2020) Management of corona virus disease-19 (COVID-19): the Zhejiang experience. Zhejiang Da Xue Xue Bao Yi Xue Ban 49(1):1

104. Gombart AF, Pierre A, Maggini S (2020) A review of micronutrients and the immune system-working in harmony to reduce the risk of infection. Nutrients 12(1):236

105. Avery JC, Hoffmann PR (2018) Selenium, selenoproteins, and immunity. Nutrients 10(9):E1203

106. Yong CC, Yoon Y, Yoo HS, Oh S (2019) Effect of lactobacillus fermentation on the anti-inflammatory potential of turmeric. J Microbiol Biotechnol 29(10):1561-1569

107. Mou H, Yang F, Zhou J, Bao C (2018) Correlation of liver function with intestinal flora, vitamin deficiency and IL-17A in patients with liver cirrhosis. Exp Ther Med 16(5):4082-4088

108. Kakodkar P, Kaka N, Baig MN (2020) A comprehensive literature review on the clinical presentation, and management of the pandemic coronavirus disease 2019 (COVID-19). Cureus 12(4): 7560

109. Xu J, Yang J, Chen J, Luo Q, Zhang Q, Zhang H (2017) Vitamin $\mathrm{D}$ alleviates lipopolysaccharideinduced acute lung injury via regulation of the reninangiotensin system. Mol Med Rep 16(5):7432-7438

110. Li Y, Kong D, Wang $\mathrm{Z}$ et al (2011) Inactivation of AR/ TMPRSS2-ERG/Wnt signaling networks attenuates the aggressive behavior of prostate cancer cells. Cancer Prev Res (Phila) 4(9):1495-1506

111. Nelson KM, Dahlin JL, Bisson J, Graham J, Pauli GF, Walters MA (2017) The essential medicinal chemistry of curcumin. J Med Chem 60(5):1620-1637

112. Hemila H, Chalker E (2019) Vitamin C can shorten the length of stay in the ICU: a meta-analysis. Nutrients 11(4):708
113. Fowler AA III, Truwit JD, Hite RD et al (2019) Effect of vitamin $\mathrm{C}$ infusion on organ failure and biomarkers of inflammation and vascular injury in patients with sepsis and severe acute respiratory failure: the CITRIS-ALI randomized clinical trial. JAMA 322(13):1261-1270

114. Wintergerst ES, Maggini S, Hornig DH (2006) Immune-enhancing role of vitamin $\mathrm{C}$ and zinc and effect on clinical conditions. Ann Nutr Metab 50(2):85-94

115. Sanders JM, Monogue ML, Jodlowski TZ, Cutrell JB (2020) Pharmacologic treatments for coronavirus disease 2019 (COVID-19): a review. JAMA. https://doi.org/10.1001/jama. 2020.6019

116. Caly L, Druce JD, Catton MG, Jans DA, Wagstaff KM (2020) The FDA-approved drug ivermectin inhibits the replication of SARS-CoV-2 in vitro. Antiviral Res 2020:104787

117. Zhou F, Yu T, Du R et al (2020) Clinical course and risk factors for mortality of adult inpatients with COVID-19 in Wuhan, China: a retrospective cohort study. Lancet 395(10229): 1054-1062

118. Tran K, Cimon K, Severn M, Pessoa-Silva CL, Conly J (2012) Aerosol generating procedures and risk of transmission of acute respiratory infections to healthcare workers: a systematic review. PLoS ONE 7(4):e35797

119. Forrester JD, Nassar AK, Maggio PM, Hawn MT (2020) Precautions for operating room team members during the COVID19 pandemic. J Am Coll Surg. https://doi.org/10.1016/j. jamcollsurg.2020.03.030

120. Wang Z, Wang W, Bai T et al (2020) Our experiences on plastic and reconstructive surgery procedures during COVID-19 pandemic from Shanghai Ninth People's Hospital Plastic and Reconstructive Surgery. Global Open J. https://doi.org/10.1097/ gox.0000000000002868

121. van Doremalen N, Bushmaker T, Morris DH et al (2020) Aerosol and surface stability of SARS-CoV-2 as compared with SARS-CoV-1. N Engl J Med. https://doi.org/10.1056/ NEJMc2004973

122. Guan W-J, Ni Z-Y, Hu Y et al (2019) Clinical characteristics of coronavirus disease 2019 in China. N Engl J Med. https://doi. org/10.1056/NEJMoa2002032

123. Li Q, Guan X, Wu P et al (2020) Early transmission dynamics in Wuhan, China, of novel coronavirus-infected pneumonia. N Engl J Med 382(13):1199-1207

124. Ong SWX, Tan YK, Chia PY et al (2020) Air, surface environmental, and personal protective equipment contamination by severe acute respiratory syndrome coronavirus 2 (SARS CoV-2 from a symptomatic patient. JAMA. https://doi.org/10.1001/ jama.2020.3227

125. Tien HC, Chughtai T, Jogeklar A et al (2005) Elective and emergency surgery in patients with severe acute respiratory syndrome (SARS). Can J Surg 48(1):71-74

126. Wren SM, Kushner AL (2014) Surgical protocol for possible or confirmed Ebola cases. American College of Surgeons. Oct 7 , 2014 (Accessed 2014 Oct 29). www.facs.org/ebola/surgicalprotocol. Accessed 28 Mar 2020

127. McAlister V (2014) Surgery in patients with Ebola virus disease. Can J Surg 57(6):364-365

128. Dexter F, Parra MC, Brown JR, Loftus RW (2020) Perioperative COVID-19 defense: an evidence-based approach for optimization of infection control and operating room management. Anesth Analg. https://doi.org/10.1213/ane.0000000000004829

129. Gralton J, Tovey E, McLaws ML, Rawlinson WD (2011) The role of particle size in aerosolised pathogen transmission: a review. J Infect 62:1-13

130. Yu ITS, Li Y, Wong TW et al (2004) Evidence of airborne transmission of the severe acute respiratory syndrome virus. N Engl J Med 350:1731-1739 
131. Santarpia JL, Rivera DN, Herrera V et al (2020) Transmission potential of SARS-CoV-2 in viral shedding observed at the University of Nebraska Medical Center. medRxiv. https://doi. org/10.1101/2020.03.23.20039446

132. Bourouiba L (2020) Turbulent gas clouds and respiratory pathogen emissions: potential implications for reducing transmission of COVID-19. J Am Med Assoc. https://doi.org/10. 1001/jama.2020.4756

133. Cook TM (2020) Personal protective equipment during the COVID-19 pandemic - a narrative review. Anaesthesia. https:// doi.org/10.1111/anae.15071

134. Kownatzki E (2003) Hand hygiene and skin health. J Hosp Infect 55:239-245. https://doi.org/10.1016/j.jhin.2003.08.018

135. Chemical Disinfectants. Guideline for Disinfection and Sterilization in Healthcare Facilities (2008) Centers for disease control and prevention, national center for emerging and zoonotic infectious diseases (NCEZID) https://www.cdc.gov/ infectioncontrol/guidelines/disinfection/disinfection-methods/ chemical.html. Reviewed September 18, 2016. Accessed 17 Apr 2020

136. Yan Y, Chen H, Chen $\mathrm{L}$ et al Consensus of Chinese experts on protection of skin and mucous membrane barrier for health-care workers fighting against coronavirus disease 2019. Dermatol Ther 2020 Mar 13:e13310. https://doi.org/10.1111/dth.13310

137. Li L, Wu A (2020, February 10) Confusion on prevention and control of healthcare-associated infection of novel coronavirus.
Retrieved from http://kns.cnki.net/KXReader/Detail?auto Login $=0 \&$ TIMESTAMP $=637171351041491250 \&$ DBCODE $=$ CJFQ\&TABLEName $=$ CAPJLAST $\&$ FileName $=$ GRKZ2020020 8000\&RESULT $=1 \&$ SIGN=S61NJ73204dEvS445VXRBDWfC Gg\%3d. Last Accessed 15 Apr 2020

\section{Appendix 1}

138. Matava CT, Yu J, Denning S (2020) Clear plastic drapes may be effective at limiting aerosolization and droplet spray during extubation: implications for COVID-19. Can J Anaesth. https:// doi.org/10.1007/s12630-020-01649-w

139. Nathan N (2020) Waste not, want not: the re-usability of N95 masks. Anesth Analg. https://doi.org/10.1213/ane. 0000000000004843

140. Li DF, Cadnum JL, Redmond SN, Jones LD, Donskey CJ (2020) It's not the heat, it's the humidity: effectiveness of a rice Cooker-Steamer for decontamination of cloth and surgical face masks and N95 respirators. Am J Infect Control. https://doi.org/ 10.1016/j.ajic.2020.04.012

Publisher's Note Springer Nature remains neutral with regard to jurisdictional claims in published maps and institutional affiliations. 